\title{
A MULTI-METHOD FOR DEFINING THE ORGANIZATIONAL CHANGE
}

Selmin Nurcan $^{*+}$, Associate Professor, Business Administration Institute - Université Paris 1 - Sorbonne

Colette Rolland*, Professor, Université Paris 1 - Sorbonne

\author{
${ }^{(*)}$ Université Paris 1 - Panthéon - Sorbonne \\ Centre de Recherche en Informatique \\ 90, rue de Tolbiac 75634 Paris cedex 13 France \\ ${ }^{(+)}$IAE de Paris (Business Administration Institute) \\ Université Paris 1 - Panthéon - Sorbonne \\ 21, rue Broca 75005 Paris France
}

\begin{abstract}
The assumption of the work presented in this paper is the situatedness of the change process. The Enterprise Knowledge Development - Change Management Method (EKD-CMM) provides multiple and dynamically constructed ways of working to organize and to guide the change management. The method is built on the notion of labeled graph of intentions and strategies called a road map and the associated guidelines. The EKD-CMM road map is a navigational structure that supports the dynamic selection of the intention to be achieved next and the appropriate strategy to achieve it whereas guidelines help in the operationalization of the selected intention following the selected strategy. This paper presents the EKD-CMM road map and guidelines and exemplifies their use with a real case study.
\end{abstract}

Key words: Organizational change, change process modeling, enterprise modeling, intention driven modeling, guidance.

\section{Introduction}

Enterprises are facing increasing pressures and competitiveness. Corporate restructuring, downsizing and reengineering are usual responses of organizations. The change is often made with explicit objectives of cost reduction and improved efficiency and effectiveness. Information Technologies (IT) are playing an important role in facilitating Business Process Reengineering (BPR). They are positioned as a unique resource that enables automation, monitoring, analysis and coordination to support the transformation of business processes [20]. Hammer and Champy define a business process as a set of activities, which produces -from one or several inputs- an output valuable for the customer [22]. The paradigm of BPR seeks to achieve performance improvement by radically reengineering the organization, whereas traditional information systems development has focused on automating and supporting existing business processes [21]. Now, organizations have the capability to create entirely new ways of working that are oriented towards customer satisfaction. In this context, achieving organizational transformation depends on the creation of a powerful vision of what future should be 
like [1].

While some companies require radical restructuring of business processes [63], others may benefit from improvement of existing operations. To control and reengineer business one needs to thoroughly understand business operations in the context of company strategic goals, company culture and in terms of business efficiency measures. The systematic modeling of business knowledge can ease this complex task of building up the understanding of the business situation [30].

The work presented in this paper addresses the organizational change management method applied in the ESPRIT project ELEKTRA The so-called Enterprise Knowledge Development - Change Management $\operatorname{Method}(E K D-C M M)$ provides a systematic way to organize and to guide the change management.

EKD-CMM is a method to documenting an enterprise, its objectives, business processes and support systems, helping enterprises to consciously develop schemes for implementing changes. Contemporary enterprises are highly complex distributed systems having many purposes and customers and involving many actors, technologies and business processes. Enterprises that can manage complexity and can respond to rapid change in an informed manner can gain a competitive advantage. The purpose of the EKD-CMM is to provide a framework for considering:

- how the enterprise functions currently,

- what are the requirements for change and the reasons for change,

- what alternatives could be envisaged in order to meet these requirements, and

- what are the criteria and arguments for evaluating these alternatives.

This paper is organized as follows. Section 2 defines the EKD-CMM views of enterprise modeling and organizational change management and introduces the EKD - Change Management Method. This section is more particularly devoted to the presentation of the EKD-CMM process model as a road map. Section 3 introduces the electronic guidebook which has been developed to guide EKD-CMM engineers and managers involved in the change process management to organize this process. Section 4 presents an example of a route that has been followed towards the road map in a real case study and develops the associated guidelines.

\section{EKD-Change Management Method: Intention based modeling of the organizational change}

EKD-CMM provides a systematic approach to develop and document enterprise knowledge and to help organizations to develop models for implementing changes. EKD-CMM satisfies two requirements: (i) assisting Enterprise Knowledge Modeling and (ii) guiding the organizational change process.

Enterprise Knowledge Modeling refers to a set of conceptual models for describing various aspects of the organization [34], [42], [47], [48], [49], [51] including enterprise business processes (roles, actors,

\footnotetext{
${ }^{1}$ The ESPRIT project ELEKTRA (N²2927) was funded the by the EC in the context of the Framework IV program.
} 
activities, objects,...) and enterprise objectives [3], [37].

Process guidance concerns the support provided to the change process definition. Work in this area mainly focuses on prescriptive approaches. However, due to its social and innovative nature, the organizational change can not be fully prescribed. In fact, the change process is a decision making process i.e. a non-deterministic process. Accordingly, process guidance should allow selecting dynamically the next task to be performed depending on the situation at hand [19], [45], [46], [52], [53], [54].

Sub-section 2.1 presents a short state-of the-art in order to situate our method among several others that have been published under similar research themes. The EKD-CMM views of enterprise modeling and organizational change management are developed in sub-sections 2.2 and 2.3 respectively. Sub-section 2.4 presents the EKD-CMM road-map which defines the multiple ways-of working (process models) offered by the method. Finally methodological guidelines associated to the map are introduced in sub-section 2.5. Some of them will be developed in section 4 .

\section{II.1. Appropriateness of the existing approaches to the change process modeling: A State of the Art}

Information System engineering and requirement engineering methods were classically focused on the product aspect of systems development and have paid less attention to the description of formally defined processes which could be supported by CASE environments.

A product is the desired output of the design process. Within EKD-CMM, the product is a set of organizational models describing the new system to be constructed and the organization in which it will operate. The process keeps track of how the product has been constructed in a descriptive manner. A process and its related product are specific to an application.

A Product Model defines the set of concepts and constraints used by an engineer for defining a product together with their properties and relationships. A Process Model is a description of processes at the type level. It defines how to use the concepts defined within a Product Model and may serve two distinct purposes: descriptive or prescriptive [6], [32]. A descriptive Process Model aims at recording and providing a trace of what happens during the development process [18], [44]. A prescriptive Process Model is used to describe "how things must/should/could be done". Prescriptive Process Models are often referred to as ways-of-working [62]. A Process Model and its related

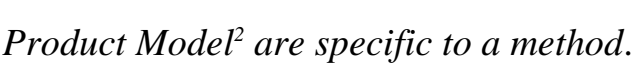

A study of the state-of-the-art on Product Models suggests that existing approaches to enterprise knowledge modeling can be classified into two categories. In the first category, an organization is represented as a set of inter-related elements satisfying collaboratively common objectives [5], [12], [17]. For instance, VSM [12] allows us to model an organization as a set of "viable" sub-systems

\footnotetext{
${ }^{2}$ We use capitalized initials in order to differentiate the method specific Models from the application specific models that compose the product.
} 
representing respectively the operation, co-ordination, control, intelligence (reasoning, analysis) and politics (strategy) aspects of an organization.

In the second category, the focus is given to developing different views (facets) of the organization dealing respectively on actors, roles, resources, business processes, objectives, rules, etc. [3], [7], [25], [30]. Business process modeling usually employs and/or combines three basic views: (i) the functional view expressed based on Data Flow Diagrams [8], (ii) the behavioral view focused on when and under which conditions activities are performed and based on state diagrams or interaction diagrams [28], and (iii) the structural view focused on the static aspect of the business process capturing the objects that are manipulated by the business process and their relationships [61]. For example, IDEF0 [59], [60] suggests a data flow perspective to define business processes while STATEMATE [23] covers the 'who, what, where, when and how' perspectives based on activity, state and module charts.

Workflow Models belong to the second category and are devoted to the representation of business processes whose execution could be automatically supported by workflow management systems. Workflow concerns, at first, an activity of scheduling and coordination of work between actors implicated in business processes. Workflow Models are numerous but there are a few theoretical studies on which they are founded. Two types distinguish themselves: a) Models coming from Petri nets (for instance, ICN), b) Models coming from the Speech Act Theory (for instance, ActionWorkflow).

According to the ICN Model [13], an information control net is a set of procedures, steps, activities, roles, and actors with a valid set of relations between these entities. The extended ICN Model [14] incorporates also the notion of goal. In the Inconcert workflow Model [39], a process (called job) consists of tasks, each of which is a unit of work that can be performed by one person. Tasks at the same level may have ordering dependencies defined among them. VPL [64] is a graphical language modeling a process as requests for tasks. Stages represent the communications needed to coordinate tasks. Each stage represents a task request, commitment or question, from one person to another, as a specific step in the process. The ActionWorkflow Model [38] considers a task as a communication relationship between two participants, a customer and a performer. A task is represented as a loop composed of four phases: preparation, negotiation, performance and acceptance. The process model is built by successive refinements. All these Product Models have some common characteristics. They use a top-down approach that enables the choice of the abstraction level of the representation and the modeling of a business process by successive decompositions. They have the same finality: to divide a complex process into a finite number of stages and to describe their flow.

A study of the state-of-the-art suggests that existing Process Models can be classified into three

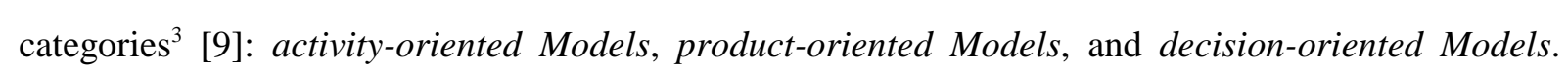

\footnotetext{
${ }^{3}$ Refer to [45] for a comparative survey of process models.
} 
Each category has an underlying paradigm that we examined in terms of its appropriateness to change process modeling.

Activity-oriented Models attempt to describe the development process as a set of activities with conditions constraining the order of these activities [11], [16], [26]. This linear view of activity decomposition is inadequate to model the organizational change process, because of all the alternatives that should be considered. Procedural representations cannot incorporate the rationale underlying the process and therefore do not permit reasoning about engineering choices based on existing alternatives. The linear view is also inadequate for ways-of-working which have to support backtracking and reuse of previous designs. These are necessary in the context of organizational change management.

Product-oriented Process Models do not put forward the activities of a process but rather the result of these activities [15], [24], [40], [65]. A positive aspect of these approaches is that they model the evolution of the product and couple the product state to the activities that generate this state. However as far as guidance is concerned, and considering the highly non-deterministic nature of the change process, it is probably difficult to write down a realistic state-transition diagram that adequately describes what has to happen during the organizational change..

The most recent type of Process Models follows a decision-oriented paradigm [29], [43], [56], [58]. The successive transformations of the product are looked upon as consequences of decisions. This type of Models allows a user to capture more process knowledge than the two other approaches. Decision-oriented Models are not only able to explain how but also why the process proceeds. Their enactment guide the decision making process that shapes the development, help reasoning about the rationale of decisions, and record the associated deliberation process ${ }^{4}$.

In summary, the expressiveness of activity and product oriented Process Models it is not sufficient for modeling change processes where human reasoning is a major component. The executions of the activities of such processes are the consequence of human decisions. Thus a decision-oriented modeling paradigm seems to be the most appropriate for the organizational change process both for trace and guidance purposes. This type of Models allow the user to trace processes, highlighting why decisions were made and thus facilitating the introduction of change in the enterprise knowledge and the enterprise processes.

However, change processes are not adequately covered in existing decision-oriented Models. At any time, a change engineer is in a situation that he/she views with some specific intention. His/her reaction depends on both these factors; i.e. on the context in which he/she is placed. He/she acts contextually [56]. Clearly, there is a high need for methods which offer process guidance to provide advice on which activities are appropriate under which situations and how to perform them [10], [55],

\footnotetext{
${ }^{4}$ See alternative scenaria evaluation in section 4.2.5.
} 
[67] to handle change management. In this section, we present a method, namely Enterprise Knowledge Development- Change Management Method (EKD-CMM) which intends to provide such guidance.

\section{II.2. The EKD-CMM view of enterprise modeling}

The Product Models underlying EKD-CMM are based on the use of Enterprise Models [3] whose purpose is to represent various views of an enterprise. A detailed presentation of the EKD-CMM Product Models can be found in [3], [4] and [36].

Our vision of the enterprise is structured in three levels of concern as shown in Figure 1: The enterprise objectives are achieved by executing the enterprise processes whose are themselves supported by the enterprise information systems.

The goal models of the first level represent the current and future enterprise objectives. Their purpose is to describe what the enterprise wants to achieve or to avoid.

Enterprises form networks of processes in order to meet their objectives. Enterprise business processes motivated by enterprise objectives are modeled at the second level according to several points of view. Consequently, enterprise process models resulting from these descriptions require different Product Models:

(a) What happens in enterprise processes can be analyzed in terms of the roles that individuals or groups play in order to meet their responsibilities. Roles correspond to sets of responsibilities and related activities. The actor/role model aims to describe how actors are related to each other and also to enterprise objectives.

(b) People perform activities to achieve enterprise objectives. The role/activity model is used to define enterprise processes, the way they consume/produce resources to achieve enterprise objectives.

(c) Activities carried out by different roles deal with business objects. Business objects set the structure of the support systems and their behavior has an identifiable life-cycle. The object model is used to define the enterprise entities, attributes and relationships.

The third level is useful when the EKD-CMM approach is applied to define also the requirements for the enterprise information system. The focus is thus the computerized system that has to support the enterprise processes in order to achieve the enterprise objectives.

Using models to represent the enterprise allows a more coherent and complete description of enterprise objectives, business processes, actors and enterprise objects than a textual description. These models are useful because they allow (i) to improve the knowledge (understanding) about the enterprise, (ii) to reason on alternative solutions and diverging points of view, and (iii) to reach an agreement. They proved their efficiency as well as for improving communication than making easier the organizational learning. 
Because we wish to model the organizational change process, we focus our attention on business processes in order to understand the current way of working of the enterprise (second level in Figure 1) and we reason on the organizational change at the intentional (first) level. Reasoning on the enterprise objectives makes easier understanding of problems and communication on essential aspects (what and why instead of who, when, where and how). This representation "by objectives" may (i) constitute a document for business analysts to discuss about the enterprise and its evolution, and (ii) help, in term, analysts, designers and developers of information systems.

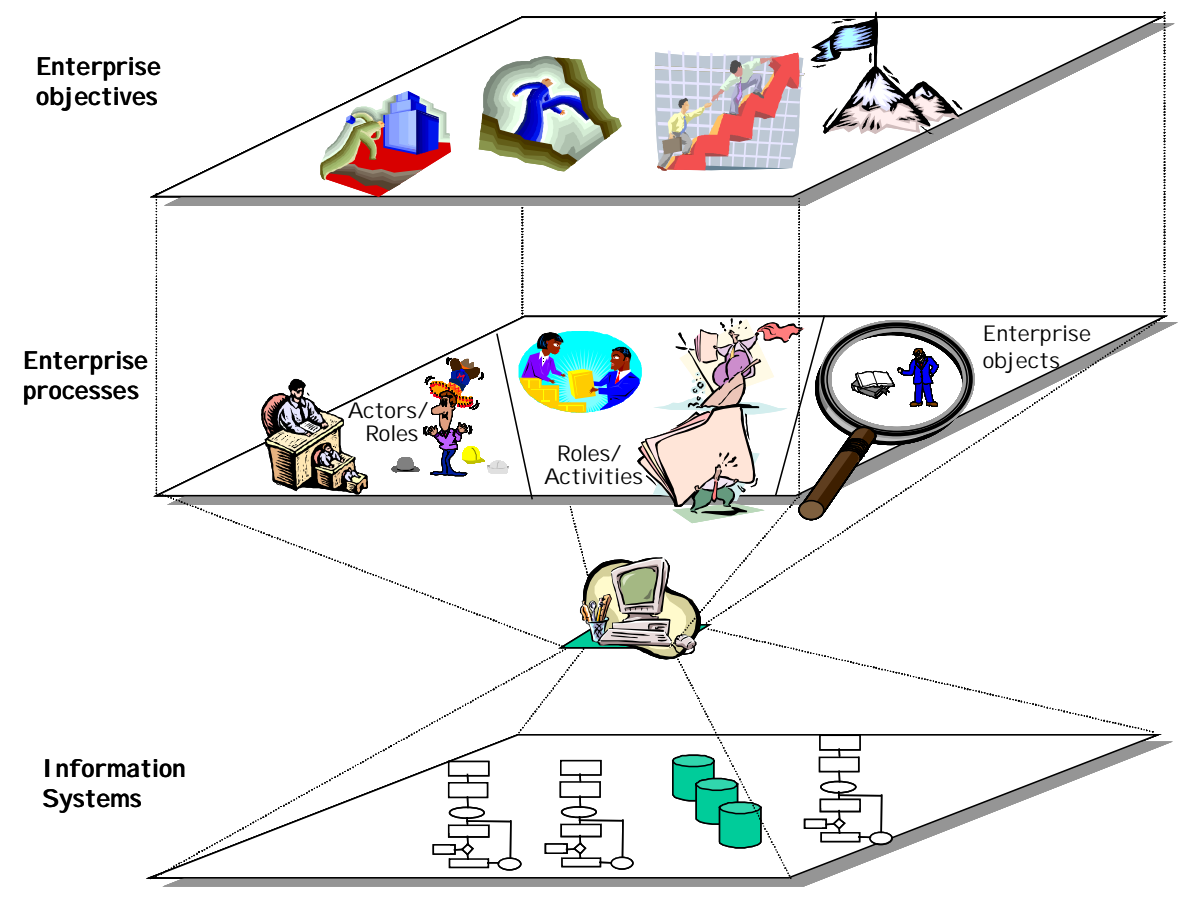

Figure 1: The EKD-CMM view of enterprise modeling 


\section{II.3. The EKD-CMM view of the organizational change management}

The need for change is typically stated in a simple manner as a change vision. A classical example is John F. Kennedy's statement: 'to send a man to the moon before the end of the decade'. Thus, the change process is the process of transforming the vision into a new model. Within the world in which the vision has to be realized, many habits (legacies) exist. Some are based on formally stated goals, policies, or competing visions. Others are just regularly observable phenomena for which no predefined structure or reasons are known a priori.

The task is therefore twofold. First, relevant habits must be analyzed and the goals, policies and visions behind them must be made explicit. This is essentially a goal-driven abstraction process from existing practice leading to the 'As-Is' model that defines the functionality and history of the existing organization. Second, the new vision must be established in this context leading to the 'To-Be' model that defines the requirements for the envisioned organization. The quality of the As-Is and To-Be models depends on the knowledge elicited from the stakeholders and their involvement in the change process. According to Jackson [27] the first model describes indicative properties whereas the second one describes optative properties. As depicted in Figure 2, mastering the change in an organization requires four major steps.

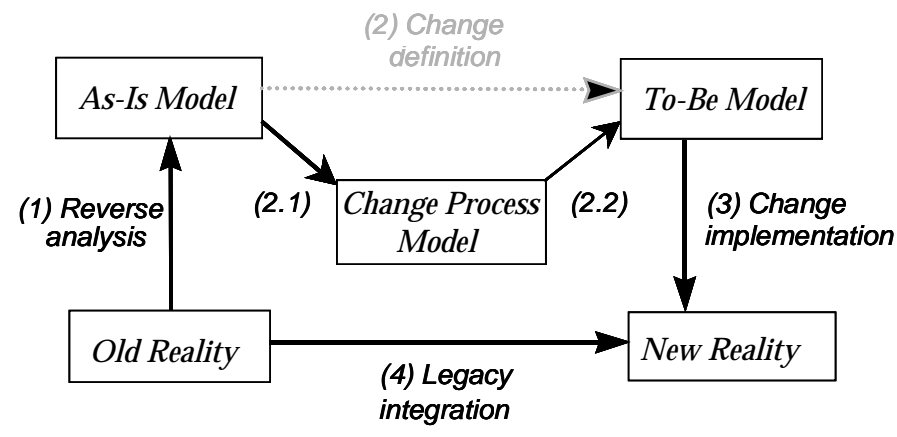

Figure 2: The EKD-CMM view of the organizational change

1 - Reverse analysis: Abstracting a model from current reality (As-Is model). In most cases, no conceptual model of the actual organization exists.

2- Change definition: Integrating the change definition into the As-Is model defining the model for the future organization (To-Be model)

3 - Change implementation: Implementing the new organization based on the To-Be model

4 - Legacy integration: Taking into account the existing context during the change implementation

Noticing this necessary juxtaposition of vision and context in an always changing environment, we define the change process as a process of establishing a vision for change in context. The change definition (step 2 in Figure 2) is itself a complex process as many alternative change routes and many 
future models can be envisioned. We propose scenaria as an appropriate means to support the definition of these alternative routes and to achieve better stakeholder involvement. Therefore, the change process model (see Figure 2) which describes how to perform the change should include the description of alternative scenaria that the enterprise could follow in order to reorganize itself to meet the specific requirements for the future and to comply with the constraints imposed to the enterprise by its environment that are called 'contextual forces'. The change process model describes all possible routes that the enterprise can follow to reach its envisioned future state in which all constraints imposed by the contextual forces will be satisfied.

Thus, EKD-CMM suggests two more tasks consisting of first, modeling the alternative scenaria for change within a change process model and secondly, selecting the appropriate scenario for change.

The EKD-CMM conceptual support for change consists in reasoning on models. As shown in Figure 2, The EKD-CMM process results in three models (the As-Is model, the To-Be model and the Change Process model) and identifies four states to be reached when performing change management. We refer to those as the four EKD-CMM states:

(1) 'As-Is' state ;

(2) 'Alternative scenaria for change determined' state ;

(3) 'Alternative scenaria evaluated and the most appropriate one selected' state ;

(4) 'To-Be' state.

EKD-CMM does not impose one way of reaching the four states but proposes several ones. In other words, there are several routes that can be followed to reach the four EKD-CMM states required for managing change. These routes are integrated in the EKD-CMM road map.

\section{II.4. The EKD-CMM Road Map}

A road map is a process model in which a non-deterministic ordering of intentions and strategies has been included. It is a labeled directed graph with intentions as nodes and strategies as edges between intentions. As shown in Figure $3^{\text {G }}$, a map consists of a number of sections each of which is a triplet $\left\langle I_{i}, I_{j}, S_{i j}\right.$. There are two distinct intentions called Start and Stop respectively that represent the intentions to start navigating in the map and to stop doing so. Thus, it can be seen that there are a number of routes in the graph from Start to Stop. The road map is a navigational structure that supports the dynamic selection of the intention to be achieved next and the appropriate strategy to achieve it whereas the associated guidelines help in the operationalization of the selected intention.

We assume change processes to be intention-oriented. At any moment, the change engineer has an intention, a goal in mind that he/she wants to fulfill. To take this characteristic into account the road map identifies the set of intentions that have to be achieved in order to solve the problem at hand.

\footnotetext{
${ }^{5}$ We use an E/R like notation. A box represents en Entity Type (ET), the labeled link represents a Relationship Type (RT) and the embedded box refers to an objectified RT.
} 
There are two key intentions in EKD-CMM, namely "Conceptualize Enterprise Business Process Model" and "Elicit Enterprise Goal Structure". We refer to them as 'Process Intentions'. “Conceptualize Enterprise Business Process Model (BPM)” refers to all activities required to construct a business process model whereas "Elicit Enterprise Goal Structure" refers to all those activities that are needed to identify goals and to relate them one another through AND, OR (exclusive OR) and AND/OR (inclusive OR) relationships. The two first are traditionally used in goal modeling [41]. The AND/OR relationship is required in order to make possible the expression of a multiple choice between several options.

A strategy is an approach, a manner to achieve an intention. The strategy, as part of the triplet $<I i, I j, \mathrm{Sij}>$ characterizes the flow from $I i$ to $I j$ and the way $I j$ can be achieved. Six strategies are used in the road map for organizational change, namely Participative Modeling Strategy, Analyst Driven Strategy, Process Clustering Strategy, Goal Deployment Strategy, Evaluation Strategy and Completeness Strategy. The road map may be extended using other strategies if they are successfully applied in different organizational change processes and prove their reusability in similar settings.

The specific manner in which an intention can be achieved is captured in a section of the map whereas the various sections having the same intention $I_{i}$ as a source and $I_{j}$ as target show the different strategies that can be adopted for achieving $I_{j}$ when coming from $I_{i}$. Similarly, there can be different sections having $I_{i}$ as source and $I_{j}, I_{j 2}, \ldots . . I_{j n}$ as targets. These show the different intentions that can be achieved after the achievement of $I_{i}$.



Figure 3: The map meta-model

The EKD-CMM road map is shown in Figure 4. As shown in this figure, there might be several flows from "Start" $\left(I_{i}\right)$ to "Elicit Enterprise Goal Structure" $\left(I_{j}\right)$, each corresponding to a specific strategy (for example <Start, Elicit Enterprise Goal Structure, Participative Modeling Strategy> and <Start, Elicit Enterprise Goal Structure, Analyst Driven Strategy>). In this sense the map offers multi-thread flows. There might also be several strategies from different intentions to reach an intention $I_{i}$ (for example $<$ Elicit Enterprise Goal Structure, Elicit Enterprise Goal Structure, Goal Deployment Strategy> and

\footnotetext{
${ }^{6}$ Intention are in italics $\left(I_{i}, I_{j}\right)$

${ }^{7}$ Strategies are in " arial narrow" $\left(\mathrm{S}_{\mathrm{ij}}\right)$
} 
$<$ Start, Elicit Enterprise Goal Structure, Participative Modeling Strategy>). In this sense the map offers multi-flow paths to achieve an intention. Finally, the map can include reflexive flows ${ }^{\mathrm{B}}$, for instance $<$ Elicit Enterprise Goal Structure, Elicit Enterprise Goal Structure, Goal Deployment Strategy>.

The road map contains a finite number of routes, each of them prescribing a way to develop the product, i.e. each of them is a EKD-CMM process model. Therefore the map is a multi-model. It embodies several process models, providing a multi-model view for modeling a class of EKD-CMM processes. None of the finite set of models included in the road map is recommended 'a priori'. Instead the approach suggests a dynamic construction of the actual path by navigating in the road map. In this sense the approach is sensitive to the specific situations as they arise in the process.

Because the next intention and strategy to achieve it are selected dynamically, guidelines that make available all choices open to handle a given situation are of great convenience. The EKD-CMM road map has such associated guidelines. A guideline is a set of indications on how to proceed to achieve an intention. A guideline embodies method knowledge to guide the change engineer in achieving an intention in a given situation.

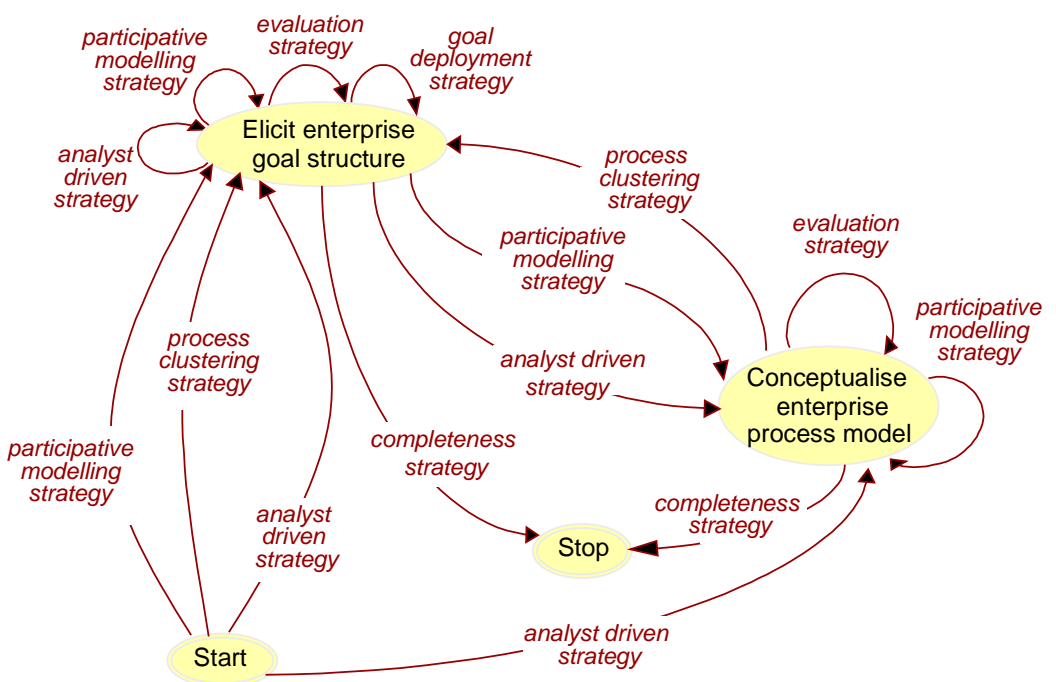

Figure 4: The road map

\footnotetext{
${ }^{8}$ a section having the same intention I as a source and a target.
} 


\section{II.5. The purpose of the EKD-CMM guidelines associated to the road map sections}

EKD-CMM guidelines are provided for each section of the road map to support the achievement of an intention following a given strategy. Some of them will be described and exemplified in section 4 .

\section{II.5.1. Follow participative modeling strategy}

The participative modeling strategy seems appropriate in the situations where the organizational maturity of modeling and the participative involvement are high, the organizational culture is flat and the degree of clarity of the problem is low. The guideline implementing this strategy is suggested thus for map sections <Start, Elicit Enterprise Goal Structure, Participative Modeling Strategy> and <Elicit Enterprise Goal Structure, Elicit Enterprise Goal Structure, Participative Modeling Strategy>, <Elicit Enterprise Goal Structure, Conceptualize Enterprise BPM, Participative Modeling Strategy> and $<$ Conceptualize Enterprise BPM, Conceptualize Enterprise BPM, Participative Modeling Strategy>. A participative modeling session is typically carried out using a large plastic sheet on the wall where participants post their descriptions of different components of the models used. After this session, the modeling experts transport the model produced on the plastic sheet into a computerized tool, analyze, restructure and refine it. Then a walk-through seminar takes place in a room equipped with means to expose the results. Finally continued work proceeds as iterations of additional analysis and restructuring work. A detailed description of this guideline can be found in [4].

\section{II.5.2. Elicit enterprise goal structure following analyst driven strategy}

The analyst driven strategy seems appropriate in the situations where the organizational maturity of modeling and the participative involvement are low, the organizational culture is hierarchical and the problem is relatively well defined. The analyst driven strategy to elicit enterprise goal structure, as well as participative modeling strategy, is based on the premise that the vision of the future does not pre-exist in the minds of the change engineers and the stakeholders but needs to be formulated through brainstorming and deliberating. Nevertheless, a low level of the maturity of modeling of stakeholders and a hierarchical culture of the organization call for more guided analyst driven cooperative modeling sessions rather than participative modeling sessions. The guideline associated to map sections <Elicit Enterprise Goal Structure, Elicit Enterprise Goal Structure, Analyst Driven Strategy> and <Start, Elicit Enterprise Goal Structure, Analyst Driven Strategy> suggests to discuss respectively (i) on the external forces which constraint the enterprise to change and on the future enterprise requirements, and (ii) on currents goals of the enterprise. This guideline will be detailed in subsection 4.2.3.

\section{II.5.3. Conceptualize enterprise goal structure following process clustering strategy}

The guideline associated to the map sections <Start, Elicit Enterprise Goal Structure, Process Clustering Strategy> and <Conceptualize Enterprise BPM, Elicit Enterprise Goal Structure, Process Clustering Strategy> suggests to abstract the goals corresponding to the current state of the enterprise 
[33] by clustering the business processes aiming to achieve the same high-level business goal and to structure them in a goal hierarchy. This guideline will be described in sub-section 4.2.2.

\section{II.5.4. Conceptualize enterprise goal structure following goal deployment strategy}

The guideline associated to the map section <Elicit Enterprise Goal Structure, Elicit Enterprise Goal Structure, Goal Deployment Strategy> supports the transformation of the hierarchy of current goals into a change process model. The goal deployment strategy focuses on the analysis of the impact of the external constraints and the future requirements on the current enterprise goals. The product of this guideline is a hierarchy of goals. It contains a particular type of goals, called change goals. Change goals tell us how to change the organization, i.e. what should be improved, what should be introduced and what should cease to be performed in the organization. The change process model describes all possible roads that the enterprise can follow to reach its envisioned future state in which all constraints imposed by the external forces and future requirements will be satisfied [50]. This guideline will be developed and exemplified in sub-section 4.2.4.

\section{II.5.5. Elicit enterprise goal structure following evaluation strategy}

The guideline associated to the map section <Elicit Enterprise Goal Structure, Elicit Enterprise Goal Structure, Evaluation Strategy> consists of revisiting the change process model in order to identify and then evaluate alternative scenaria against pre-defined criteria. Based on this evaluation, comparisons of alternative scenaria occur and recommendations are made concerning the most appropriate scenaria [35]. The application of this guideline leads to the organizational change state 'alternative scenaria evaluated and one selected'. This means that the end of the change management route is reached and the Completeness Strategy suggests stopping. This guideline will be developed in sub-section 4.2.5.

II.5.6. Conceptualize current enterprise business process model from start following analyst driven strategy

The guideline associated to the map section <Start, Conceptualize Enterprise BPM, Analyst Driven Strategy> suggests to EKD-CMM analysts to observe the current context of the enterprise using a number of knowledge sources including interviews with business experts, questionnaires completed by business experts, existing literature relevant to the business domain, documentation of existing systems, etc. and then to model it using enterprise business process [33]. This guideline will be developed in sub-section 4.2.1.

II.5.7. Conceptualize future enterprise process model from future goal structure following analyst driven strategy

The guideline associated to the map section <Elicit Enterprise Goal Structure, Conceptualize Enterprise BPM, Analyst Driven Strategy> should support EKD-CMM analysts to operationalize the future goal structure using various enterprise business process models (sub-section 2.3). This guideline, being in certain manner less related to change management, has not been developed in this work. 


\section{The electronic guidebook}

\section{III.1. The electronic guidebook structure}

\section{III.1.1. A hierarchy of usage intentions}

The main objective of the EKD-CMM electronic guidebook is to guide the selection and application of a route in the EKD-CMM road map. To this end, it guides the engineer involved in change management to select the route appropriate to the situation at hand. It helps him/her to select the task to be executed next in this route; and it guides the task performance by the means of guidelines associated to the traversed map sections. However, the electronic guidebook provides knowledge not only to guide stakeholders involved in the change process, but also to understand EKD-CMM framework. The hierarchy of usage intentions shown in this figure represents the indexing of the EKDCMM knowledge base as a goal graph. Thus, as shown in Figure 5 the electronic guidebook comprises three main parts that are identified by the three usage intentions: Understand the $U$ se of the EKD CM M Electronic Guidebook, U nderstand EKD-CM M Change M anagement Framework and A pply EKD -CM M .

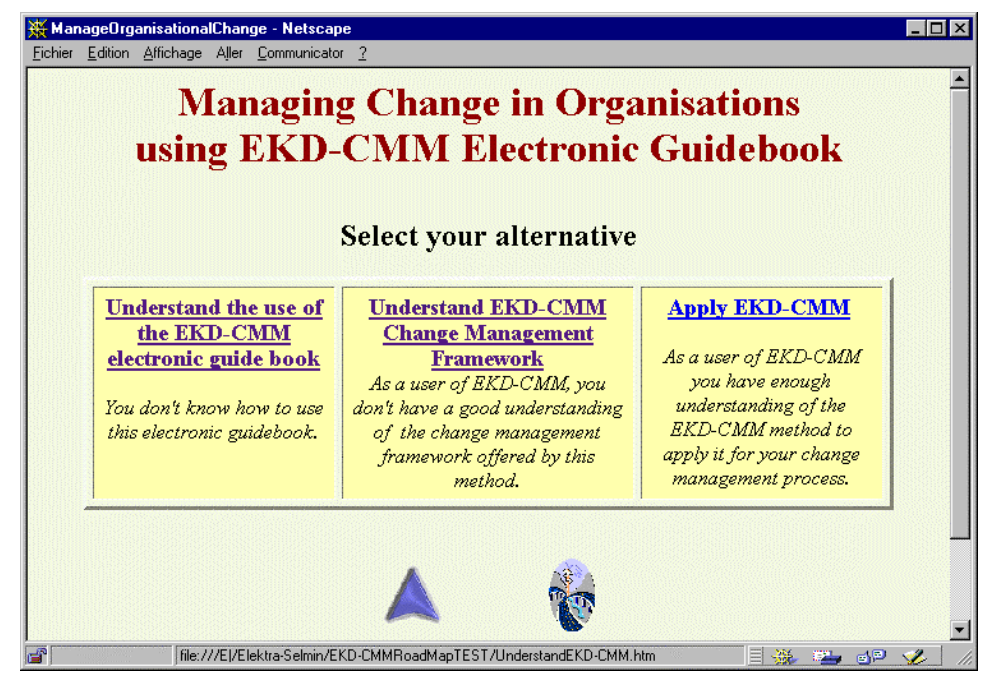

Figure 5: The step by step navigation in the EKD-CMM electronic guidebook

- The first part, called U nderstand the U se of the EKD-CM M Electronic Guidebook, describes how to navigate in the guidebook. This can be carried out in two ways:

- using the EKD-CMM electronic guidebook usage intentions hierarchy (see Figure 6), or

- step by step selecting one of the three main entry points (see Figure 5) and then browsing page to page using the arrow buttons: the up-arrow to move to the previous level in the intention hierarchy, the right-arrow to move to the next intention at the same level in the intention hierarchy, and the left-arrow to move to the previous intention at the same level.

- The second part, called Understand EKD-CM M Change M anagement Framework, explains the EKD-CMM way of thinking, introduces the various components of the EKD-CMM way of 
modeling (models and tools), and describes the different ways of working for managing the organizational change using EKD-CMM by the means of the EKD-CMM road map and its associated guidelines.

- The third part, called A pply EKD-CM M , provides the multiple ways of applying EKD-CMM and gives access to the corresponding guidelines.

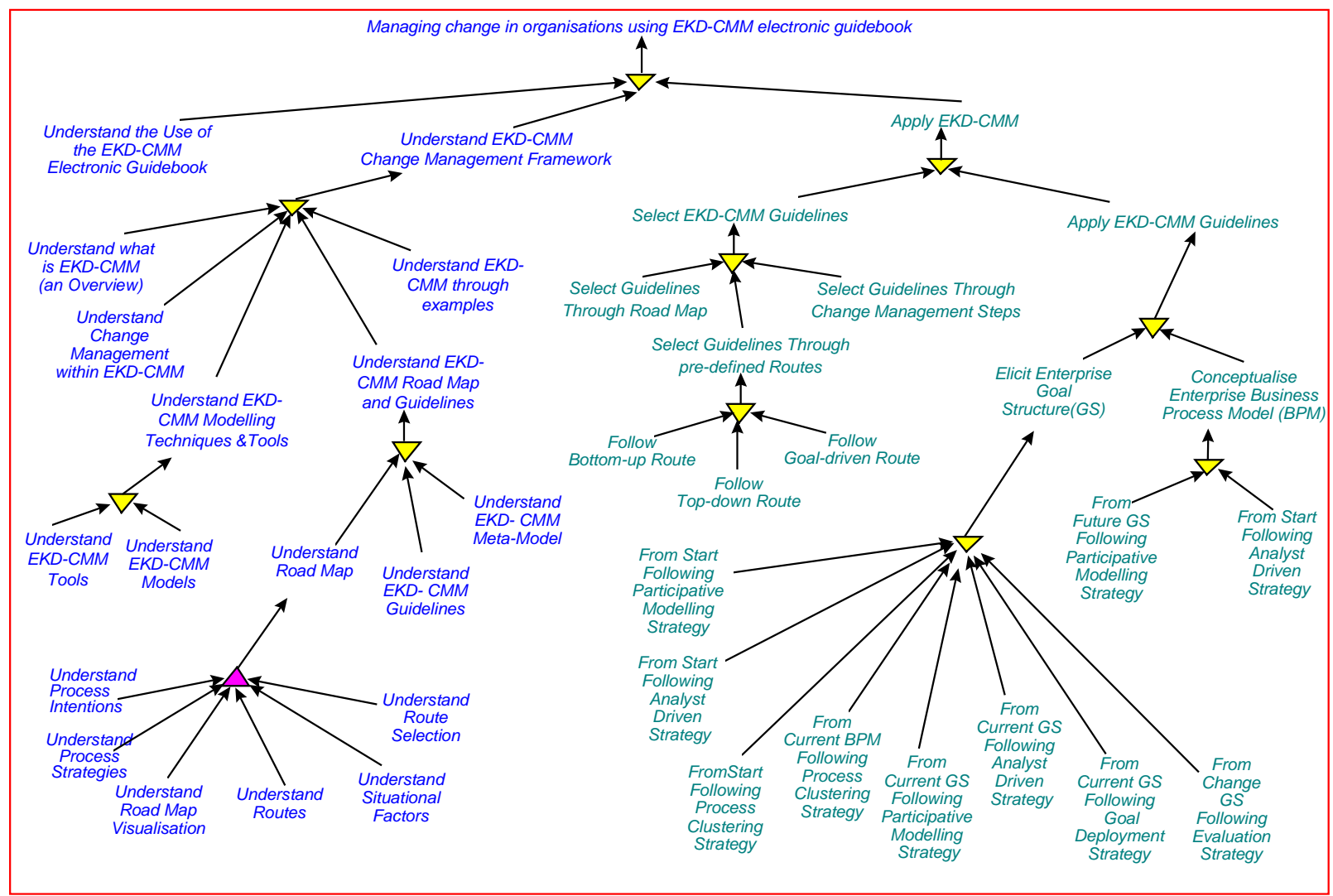

Figure 6: The hierarchy of usage intentions of the EKD-CMM electronic guidebook

\section{III.1.2. Typology of guidelines}

Following [57] we consider a method as embedding a set of guidelines. In the context of EKD-CMM, a guideline suggests how to progress at a given point of the EKD-CMM process, how to fulfill a modeling intention that an EKD-CMM user may have. A guideline might be looked upon as a structured module of knowledge for supporting decision making in the EKD-CMM process.

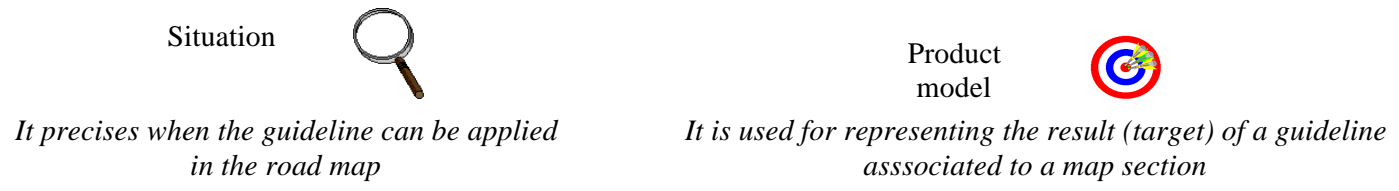

Figure 7: Symbols used in the description of EKD-CMM guidelines

Guideline representation is based upon the formalism developed in the NATURE project [19]. A guideline has a signature defined as a pair $<$ (situation), intention $>$. A situation is a part of the product it makes sense to make a decision on. It indicates when the guideline can be applied. What we mean 
here by product refers to the different application specific EKD-CMM models. An intention represents a goal a change engineer wants to fulfill at a given point in time when he/she uses the EKD-CMM method for managing change in organizations. All the EKD-CMM guidelines available in the guidebook follow these definition and are described with respect to the following template:

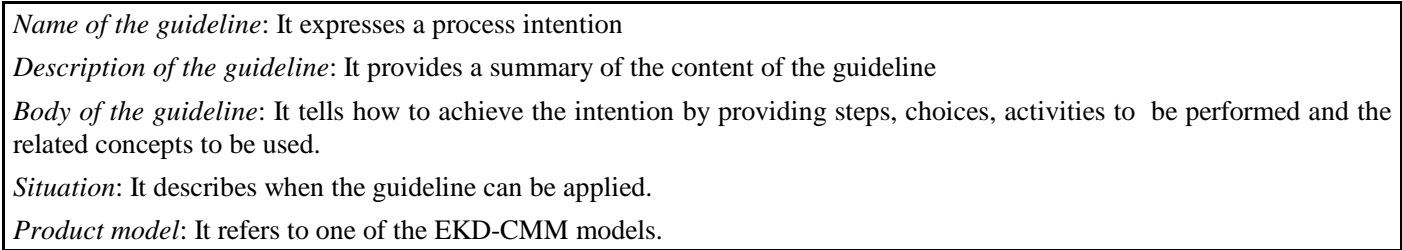

EKD-CMM guidelines are organized into hierarchies. Links between guidelines are of two kinds: refinement links allowing the refinement of a large-grained guideline into finer ones and composition links for the decomposition of a guideline into component guidelines. Guidelines are of three types, namely choice, plan and executable. The EKD-CMM method knowledge is defined as a hierarchy of guidelines having executable ones as leaves of this hierarchy. Browsing this hierarchy, the change engineer gets more and more fine-grained guidance.

When progressing in the EKD-CMM process, the change engineer may have several alternative ways to solve an issue. Therefore, he/she has to select the most appropriate one among the set of possible choices. In order to model such a piece of EKD-CMM process knowledge, we use the first type of guideline, namely the choice guideline. The body of a Choice Guideline offers different alternative ways for achieving the process intention. Arguments are provided to help in the selection of the most appropriate alternative. Alternatives of a choice guideline are guidelines too.

In order to represent situations requiring a set of decisions to be made for fulfilling a certain intention, the EKD-CMM process modeling formalism includes a second type of guideline called Plan Guideline. A plan guideline can be looked as dealing with a macro issue which is decomposed into sub-issues, each of which corresponds to a sub-decision. Components of a plan guideline are also guidelines. For example, the guideline associated to the map section <Elicit Enterprise Goal Structure, Elicit Enterprise Goal Structure, Goal Deployment Strategy> is a plan guideline composed of two component guidelines, namely Construct change goals hierarchy, and Attach processes as shown in Figure 8. 


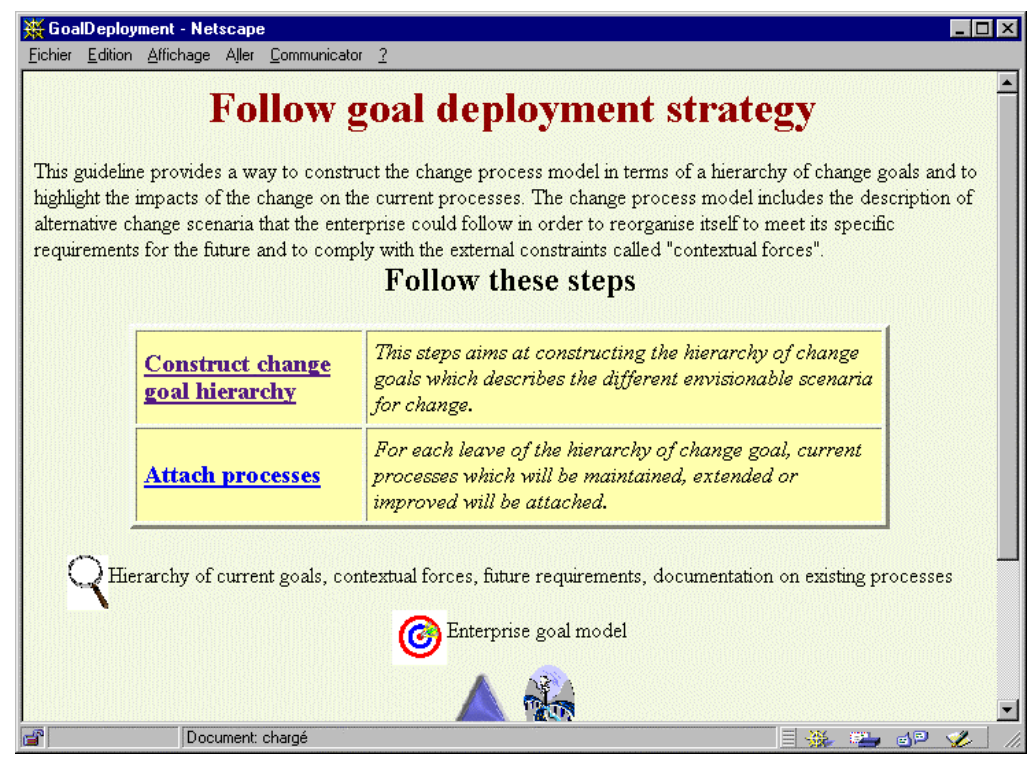

Figure 8: An example of plan guideline:

Elicit Change Goal Structure from Current Goal Structure following Goal Deployment Strategy

An Executable Guideline corresponds to an operationalizable intention that is directly applicable through a set of activities. The body of an executable guideline proposes a set of activities to be performed for achieving its process intention. For instance, the guideline associated to the map section <Elicit Enterprise Goal Structure, Elicit Enterprise Goal Structure, Analyst Driven Strategy> suggests to perform the activities described in sub-section 4.2.3.

\section{III.2. The electronic guidebook contents}

In this section we illustrate the following intentions of the usage intention hierarchy (see Figure 6): Understand EKD -CM M Change M anagement Framew ork, Select EKD-CM M guidelines and A pply EKD-CM M guidelines.

\section{III.2.1. Understand EKD-CMM Change Management Framework}

This page aims to help the change engineer to understand the EKD-CMM change management framework. It provides links to other pages that develop the EKD-CMM way of thinking (U nderstand Change M anagement within EKD-CMM), the EKD-CMM way of modeling (Understand EKD CM M M odeling Techniques and Tools) and its multiple ways of working (Understand EKD-CMM Road Map and Guidelines).

\section{III.2.2. Select EKD-CMM guidelines}

The first sub-branch of the Apply EKD-CM M part of the electronic guidebook, called Select EKDCM M guidelines, offers three guided ways to select the guideline the change engineer has to apply next: through the EKD-CMM road map, through a step in a route or through change management steps.

(i) As we have already mentioned, the EKD-CMM road map (see Figure 4) proposes flows to navigate from one intention to another using given strategies. One way of progressing in the 
change management process is to select the intention to perform next, and to select one of the possible strategies (if several) to flow to this intention. Select guidelines through road map intention of the indexing hierarchy allows the change engineer to identify the guideline supporting the achievement of the intention he/she wants to fulfill based on the EKD-CMM road map.

(ii) The usage intention named Select guidelines through pre-defined routes allows the change engineer to visualize the steps of the three routes implemented in the EKD-CMM electronic guidebook. Their stepwise descriptions shall be considered as reminders of these routes. They might be used during an EKD-CMM project, to visualize the route that is followed. If the change engineer decides to apply the EKD-CMM guidelines by selecting them through an example of a pre-defined route, he/she should first choose the route to follow as shown in Figure 9.

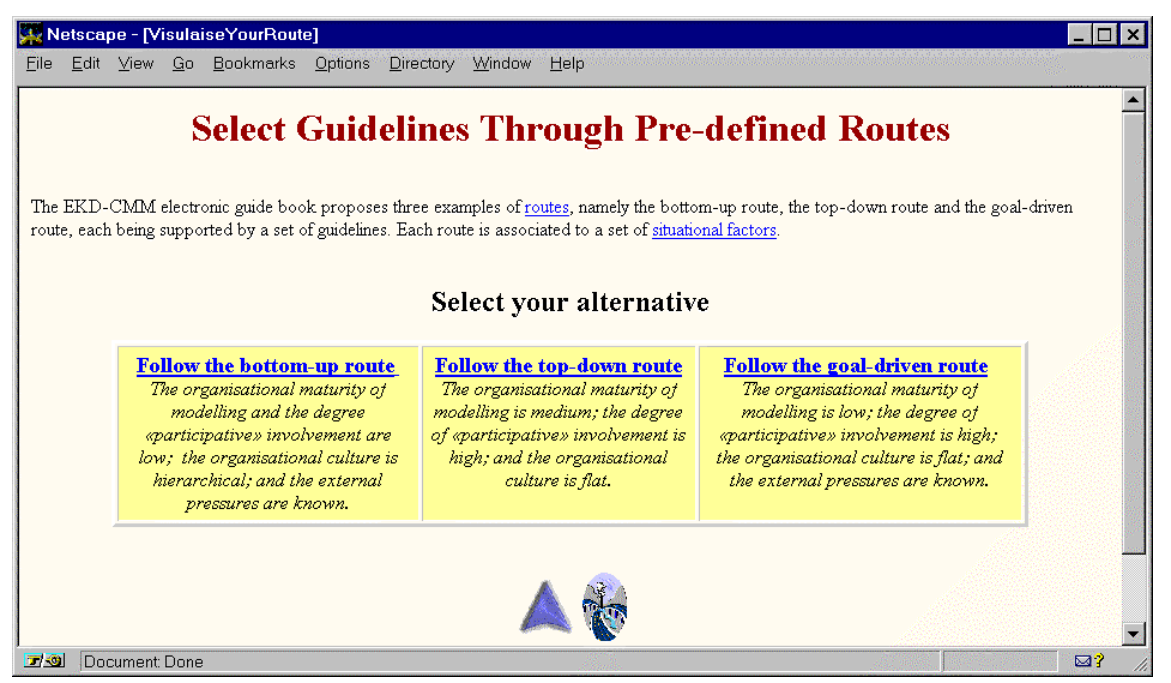

Figure 9: Three examples of routes implemented in the EKD-CMM electronic guidebook

Let us suppose that in the situation at hand, the maturity of modeling of the organization and the degree of participative involvement are low, the organizational culture is hierarchical, and the external pressures are known. Therefore, as the situation matches the factors for the bottom-up route, this route is selected (see Figure 10). The selection of the step to carry out next in the route identifies the guideline (the corresponding hypertext link) which supports this step as shown in Figure 10.

(iii) The usage intention named Select guidelines through change management steps allows the change engineer to identify the guideline to be followed according to the change management step he/she wants to carry out. Figure 11 shows the page of the guidebook indexed by the usage intention Select guidelines through change management steps. 


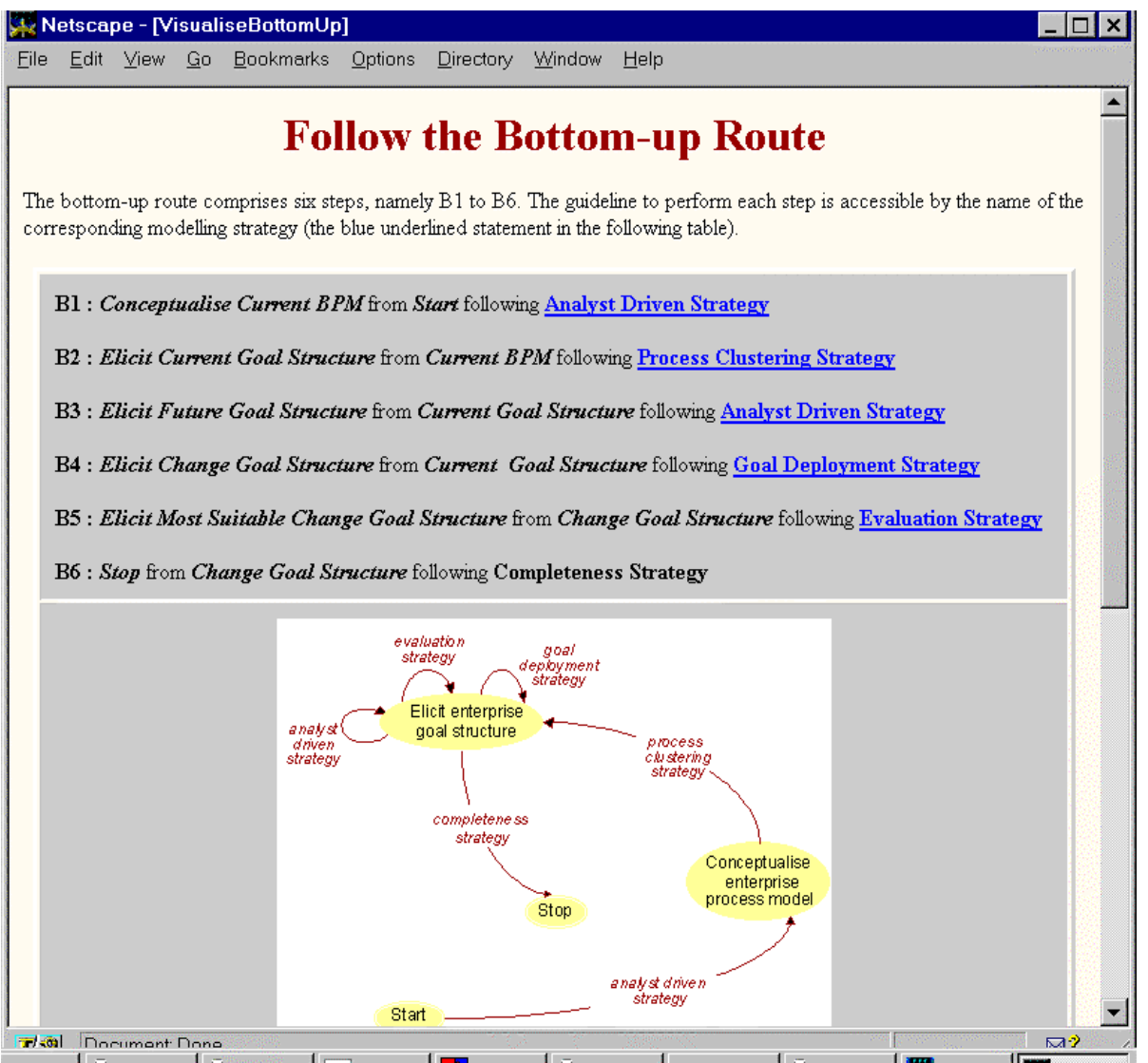

Figure 10: Applying EKD-CMM by selecting guidelines through the 'bottom-up route'

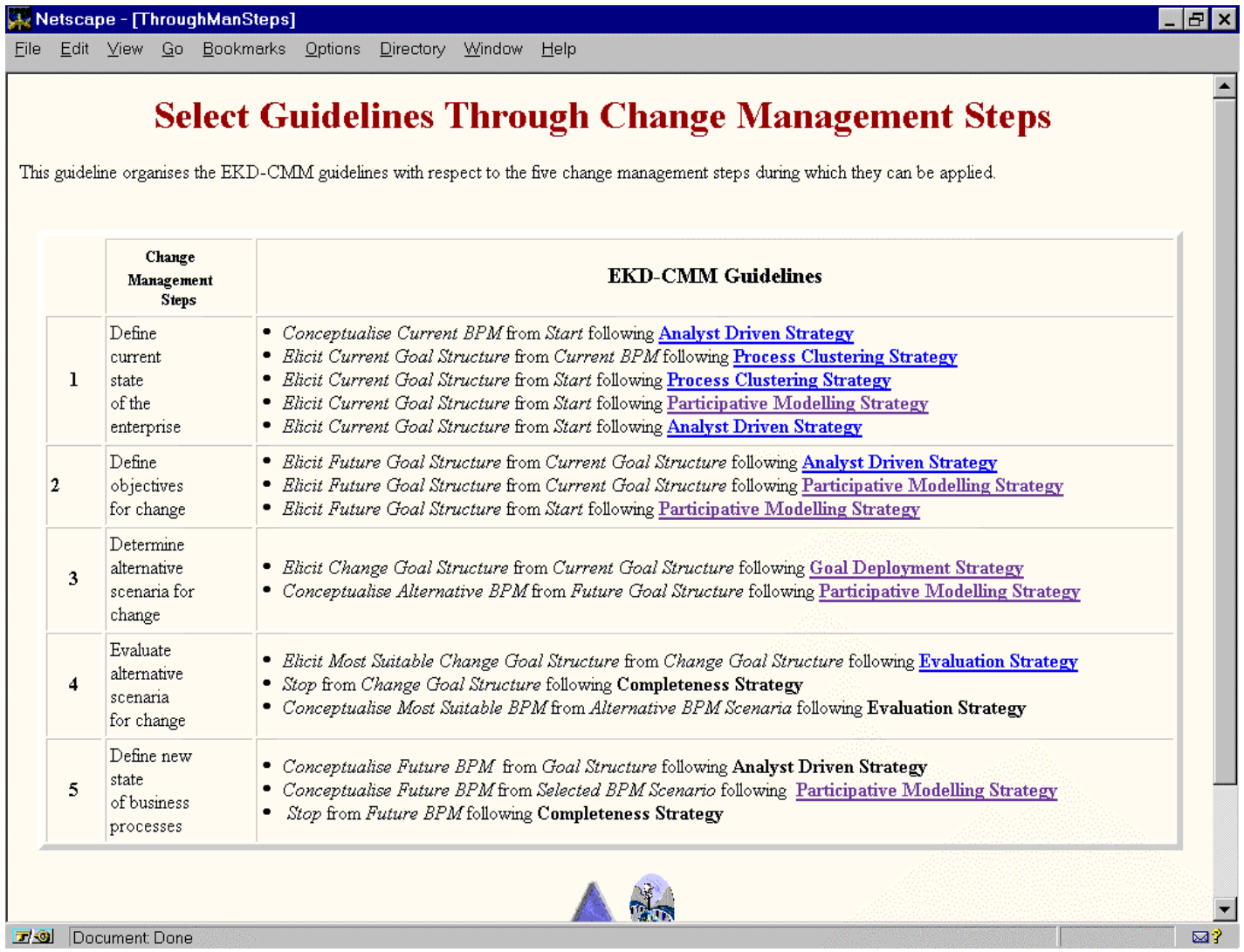

Figure 11: Applying EKD-CMM by selecting guidelines through change management steps 
Thus, the Select EKD-CMM guidelines sub-branch of the intention hierarchy allows the change engineer, first to decide in which manner he/she wants to be guided, second to select the methodological guideline he/she has to apply next in a guided way, and third to apply it using the corresponding hypertext link embedded in the page of the guidebook chosen in the first step.

\section{III.2.3. Apply EKD-CMM guidelines}

The second sub-branch of the Apply EKD-CMM part of the electronic guidebook, called Apply EKD-CM M guidelines, is suitable if the change engineer is knowledgeable enough of what he wants to do next in order to select the guideline to be applied next directly. This sub-branch contains the EKD-CMM available guidelines. There is one guideline to be applied for each map section. The page of the guidebook indexed by the intention Apply EKD-CMM guidelines offers choices with arguments to help in the selection of the appropriate alternative.

\section{An example of application of EKD-CMM and description of the suggested guidelines}

The work presented in this section is part of an industrial application concerning the deregulation of a large European electricity company with a particular focus on the company's distribution business unit. This unit is responsible for the delivery of electricity to consumers and the merchandising of electricity services. Currently, this company operates in a monopoly market. However, it is in the process of redesigning its business structure and planning reforms for the future, in anticipation of the opening of the European electricity market. This is especially critical in the distribution business unit, which is the interface of the company with the final customer.

\section{1. An example of route in the EKD-CMM road map}

The purpose of this section is to highlight the use of the EKD-CMM guidebook to carry out the four states of the organizational change described in section 2.3. This will be done following the bottomup route. Indeed, the context of the studied company corresponds to a low level of the organization maturity of modeling and well-known external pressures. Therefore, the bottom-up route is preferred. This route begins by discovering the current situation before proceeding to defining the possible transformation options. In terms of the EKD-CMM road map, this route is highlighted in figure 10. In the remainder of this section we describe each of the sections illustrated in figure 10 and listed underneath.

MS1: <Start, Conceptualize Enterprise Business Process Model, Analyst Driven Strategy >

MS2: <Conceptualize Enterprise Business Process Model, Elicit Enterprise Goal Structure, Process Clustering Strategy $>$

MS3: <Elicit Enterprise Goal Structure, Elicit Enterprise Goal Structure, Analyst Driven Strategy >

MS4: <Elicit Enterprise Goal Structure, Elicit Enterprise Goal Structure, Goal Deployment Strategy>

MS5: <Elicit Enterprise Goal Structure, Elicit Enterprise Goal Structure, Evaluation Strategy >

MS6: <Elicit Enterprise Goal Structure, Stop, Completeness Strategy > 


\section{2. Application of associated guidelines along this route}

\section{IV.2.1. Describing current enterprise business processes: 'As-Is' state}

As shown in figure 10, the first step in this route constitutes the discovery of the existing organizational state (i.e., reaching the $\mathcal{A} s-I s$ state). The guideline associated to the map section MS1 suggests the use of the EKD-CMM enterprise business process models (see sub-section 2.2) and proposes the following activities:

- To observe the current state of the enterprise by interviewing top managers and domain experts. The observation of the current state of the enterprise aims to understand the enterprise processes, to identify actors and resources which are involved, the dependencies between actors and the business objects which are used in the enterprise processes.

- To define role/activity diagrams: This activity leads to the description of the way enterprise processes consume/produce resources to achieve the enterprise objectives. Actors involved in a business process perform one or several activities according to a predefined sequence. The set of activities performed by an actor in a process defines a role as shown in Figure 12.

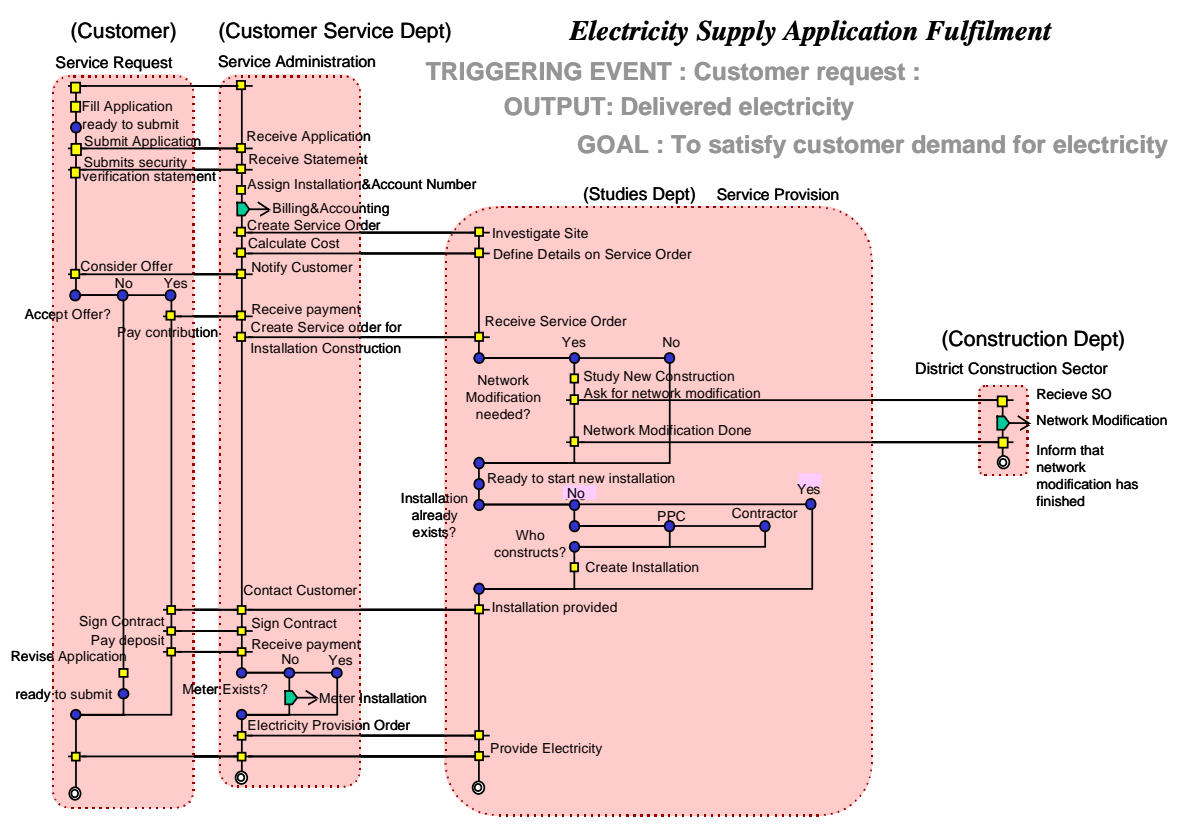

Figure 12: Example of role/activity diagram

- To define actor/role diagrams: This activity completes the description of business processes by identifying the actors (individuals or groups) playing the involved roles in order to meet their responsibilities and describing the dependencies (authority, resource, coordination, goal) between involved roles.

- To define class/association, state transition and event diagrams: This activity aims to define first business objects that are used in the enterprise processes. Then, event diagrams describing the impact of what happens in the enterprise on these objects are produced. For instance, for a new connection 
request a new account is created. Finally, for each identified object, its life-cycle describing the state changes induced by the events previously represented are described in a state transition diagram.

- Check consistency between static and dynamic views of the enterprise processes: This activity verifies if objects required for the performance of business processes as described in the role/activity diagrams are defined in the class/association diagrams, if all operations triggered by events described in event diagrams correspond to activities described in the corresponding role/activity diagrams, etc.

In the studied case, EKD-CMM analysts, using various knowledge sources as listed in section 2.5.6, carried out the conceptualization. The result was a set of models for over 150 business processes documented in terms of Actor/Role Diagrams, Role/Activity Diagrams, etc...

\section{IV.2.2. Abstracting current enterprise goals: 'As-Is' state}

The goals realized by existing processes [31], [36] were then abstracted from the process descriptions and structured in a goal hierarchy, thus establishing the connection between the current enterprise purpose and behavior. In fact, the guideline associated to the map section MS2 suggests defining the goal hierarchy of the enterprise corresponding to its current state, by clustering the business processes aiming to achieve the same high-level business goal. It includes the following activities:

- To identify goals reached by current enterprise processes by interviewing top managers and/or domain experts: A business process provides some desired output to an internal or external customer. Roughly speaking, when a process is defined at a detailed level, the delivery of the output can be considered as the operational goal attached to the process.

- To identify macro-processes and the corresponding enterprise goals by performing modeling sessions: Processes do not operate independently but are related in different ways. (i) They can have temporal relationships expressing the triggering of a process by another one; (ii) A process defined in a detailed way at the operational level can be seen as an activity in a macro-process. This leads to the identification of macro-processes characterized by higher level goals.

- To organize enterprise goals in a goal hierarchy: The recursive application of the process aggregation mechanism leads to the construction of a hierarchy of goals describing the current objectives of the enterprise. The leaves of this hierarchy correspond to operational goals.

Figure 13 shows an excerpt of the current goal hierarchy obtained by the application of this guideline in our case study. Leaf goals in this hierarchy are operational goals corresponding to specific enterprise processes. Higher-level goals were abstracted from these operational goals based on their intentional affinities. 


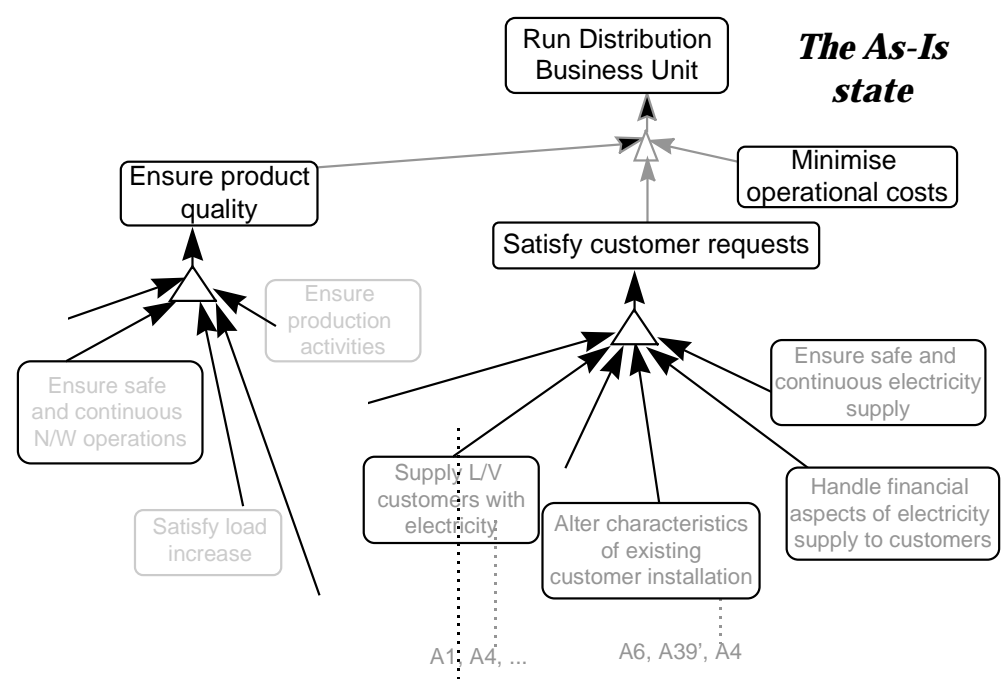

Figure 13: An excerpt of the hierarchy of current goals

\section{IV.2.3. Defining contextual forces and future requirements: Envisioned 'To-Be' state}

Reaching the $\mathcal{T} o-\mathcal{B} e$ state was then conducted in an analyst driven approach as indicated in the map section $M S 3$. This resulted in the specification of both contextual forces which constraint the enterprise to change as well as future enterprise requirements. A contextual force is an external constraint to the company that shall be taken into account while studying changes. In our case, "Change the distribution business unit to comply to the EU rules", "Introduce means for Third Party Access", "Enter the competition market" are examples of contextual forces. Future requirements are the goals describing the envisioned future state of the company. For instance, "Improve customer services", "Introduce new technologies" are examples of future requirements of the distribution business unit of the studied company. The guideline associated to this map section suggests a cooperative approach. It allows to participants to: (a) loosely define and rationalize issues regarding the future situation, (b) refine and categorize future requirements, (c) prioritize requirements through a variety of voting procedures, (d) analyze interdependencies between the requirements, (e) hinder dominant participants so that they did not adversely affect the outcome.

The whole process was assisted by the use of Ventana GroupSystems@ [66]. GroupSystems is a suite of team-based decision software tools that were used for the identification, elaboration and resolution of requirements. By engaging in such activities the participants managed to agree on a number of critical issues relating to the future of Distribution. The identified requirements were extensively discussed and rationalized in a process that necessitated several sessions involving both strategic and operational Distribution personnel.

Figure 14 shows the future requirements of the Distribution Business Unit concerning new markets. Two other hierarchies have been constructed using this guideline concerning the improvements for solving problems that exist in the current state of the company and contextual forces, respectively. 


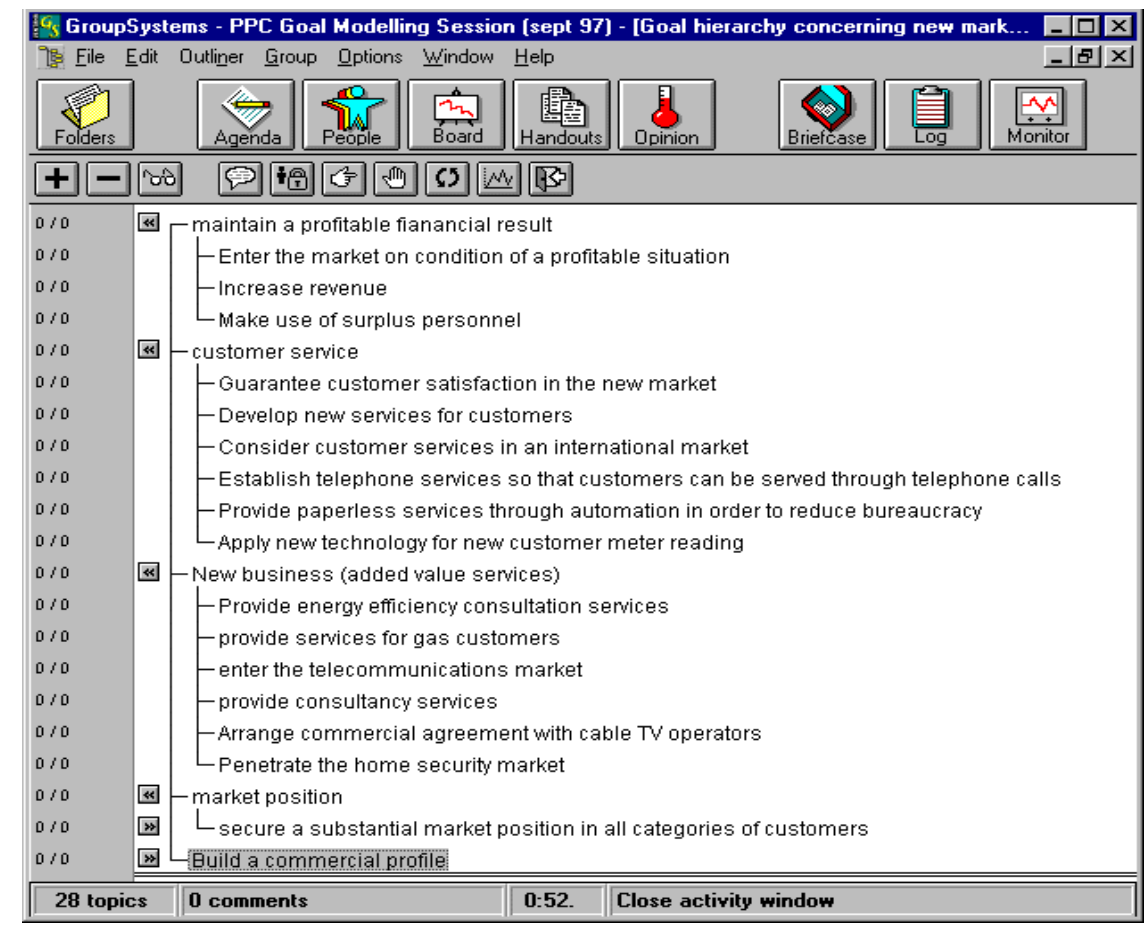

Figure 14: An excerpt of the hierarchy of future requirements for new markets

IV.2.4. Determining alternative scenaria for change: 'Alternative scenaria for change determined' state

Having discovered the existing enterprise situation and identified future requirements, the next step in the bottom-up route was to identify the effect of future requirements on the current organizational structure thus providing a basis for a reasoned approach for future improvement. This corresponds to the road map section $\mathcal{M S} 4$ that suggests a goal deployment strategy and supports the transformation of the hierarchy of current goals produced in the map section MS2 into a change process model, taking into account contextual forces and future requirements.

The guideline associated to this map section suggests to progressively generate the hierarchy of change goals by studying the impact of the contextual forces onto the current goals and to highlight the impacts of the change on current business processes. First, the current goal hierarchy is considered in a top down manner starting by the top level goal and examining its descendants step by step, until the leaves are reached. The hierarchy of change goals which describes the alternative scenaria for change is constructed accordingly, in a top down manner, step by step, by generating the change goals either as improvements of the current goals or by introducing new goals (see Figure 15). Then, for each leaf of the hierarchy of change goals, current processes that will be maintained, extended or improved are attached to the goals (see Figure 8).

Roughly speaking the process followed in constructing the change goal hierarchy iterates for each goal in the current goal hierarchy on the two main activities: 'deploy goals' and 'add new goals'. The 
former organizes goal deployment by studying the impact of the contextual forces on the current goals, eliciting and introducing the change goals reflecting the impact and envisioning alternative solutions. The latter suggests to introduce new goals that complement a goal elicited during the deployment step, to introduce alternative goals and to develop in detail all goals that have been introduced. This iterative process which is formally described by the following algorithm is encapsulated into the guideline associated to the section MS4 of the EKD-CMM road map.

For each goal $G$ in the current goal hierarchy and its immediate sub-goals $\mathrm{SG}_{\mathrm{i}}$

For each contextual force $C F$

1) Deploy $\left(G, S_{i}\right)$ with regards to $C F$

For each sub-goal $S G_{i}$

1.1. Determine impact of $\mathrm{CF}$ on $\mathrm{SG}_{\mathrm{i}}$

1.2. Define the corresponding change goal $\mathrm{C}_{\mathrm{i}}$, and introduce it in the hierarchy

1.3. Envision alternative goals $\mathrm{C}_{\mathrm{ij}}$ for $\mathrm{C}_{\mathrm{i}}$, and introduce them in the hierarchy

2) Add new goals

2.1. Envision complementary goals $\mathrm{C}_{\mathrm{k}}$ and introduce them in the hierarchy

2.2. Envision alternative goals $\mathrm{C}_{\mathrm{a}}$ and introduce them in the hierarchy

2.3. Develop goals $\mathrm{C}_{\mathrm{k}}$ and $\mathrm{C}_{\mathrm{a}}$

As an illustration of the goal deployment process, let us consider Figures 13 and 15 which describe respectively, the Distribution Unit current top level goals (those in black in Figure 13) and the chunk of the change process model resulting of the application of the goal deployment guideline.

It shall be noticed that step 1 is always applied to a current goal $(\mathrm{G})$ together with its sub-goals $\left(\mathrm{SG}_{\mathrm{i}}\right)$. This structure is referred as a 'basic block'. Thus, each iteration in the process deploys a current goal based on the analysis of the corresponding basic block (goals in bold in Figure 13).

Step 1 consists in determining the impact of the contextual force $\mathrm{CF}$ on each $\mathrm{SG}_{\mathrm{i}}$. There are four ways to type the impact of a contextual force on a current goal. The type 'improve' shall be used when there is no need to drastically change the current goal but rather to perform some improvements to increase the efficiency of the current practices. The type 'maintain' shall be used when there is no need to change the current goal but to keep it as it is. The type 'cease' shall be used when there is a need to withdraw a current goal that is considered to be no longer beneficial for the enterprise. The type 'extend' shall be used when the current goal is still valid but there is a need to enlarge its scope (e.g.. to add a new functionality, etc.). Accordingly, a change goal is elicited based on the type of impact and the current goal being impacted.

In the case study, clearly when the company's Distribution Unit will 'enter the competition market', the company will have to deal with two types of customers: the non-eligible customers and the eligible ones. The impact of the contextual force is therefore twofold. The former consists to turn the current goal " satisfy customer requests" into 'Improve existing processes to " serve efficiently non- 
eligible customers"'. The latter will be taken into account during the sub-step 2.1. In a competitive environment having a good quality product is maybe not enough and instead, it is necessary to improve the current processes in order to "Exploit distribution network in a competitive environment". More importantly, Distribution Unit should move from a situation where to "Minimize operational cost" was a satisfactory objective to a situation where it is necessary to "Become financially efficient and competitive".

When all change goals corresponding to the possible impacts have been introduced in the hierarchy, sub-step 1.3 consists in identifying alternative scenaria for them. In fact, a change goal can be achieved in several alternative ways with respect to different factors (quality requirements, market opportunity, technology availability, etc.). Envisioning alternative change goals means describing all possible alternative ways for fulfilling the change goal. For instance, the electricity company identified two ways to serve efficiently non-eligible customers: by improving/adapting the current practices or by introducing an intelligent front desk. These two alternative change goals "Serve efficiently non-eligible customers" and "Introduce intelligent front desk to serve efficiently noneligible customers " are therefore introduced in the hierarchy (see Figure 15).

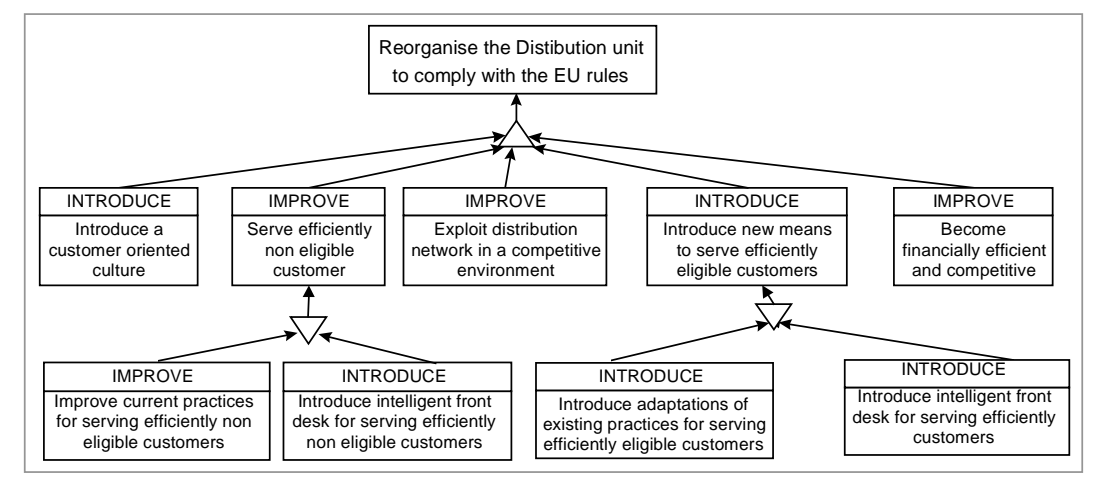

Figure 15: The resulting excerpt of the change process model

Sub-step 2.1 consists in introducing new complementary goals $\mathrm{C}_{\mathrm{k}}$ which could be necessary to comply with the change goal $\mathrm{C}$. The fifth type of change goal, namely 'introduce', shall be used when a change goal is totally new to the enterprise with regard to its current goals. The task when adding new change goals consists in envisioning new complementary goals that should be necessary to comply with the change goal considered in the situation. For instance, it is clear that competitiveness will depend to a large extend of the customer satisfaction and requires to train the company's personnel. Therefore, the complementary change goal "Introduce a customer oriented culture" has been added in the change process model. In the same manner, because of the eligible customers to whom the Distribution Unit should provide new services, a new goal is set, namely, "Introduce new means to serve efficiently eligible customers ".

It shall be noticed that the impact analysis in this example results in adding complementary goals, introducing alternative manners of proceeding and improving current goals. The hierarchy of Figure 15 
is an excerpt of the change process model and reflects the impact analysis for change. The processes attached to the three current goals will have to be improved in the light of the following change goals "Become financially efficient and competitive", "Exploit distribution network in a competitive environment" and "Improve current practices for serving efficiently non eligible customers".

In addition, complementary processes will have to be defined in order to cope with the new goals, namely "Introduce a customer oriented culture", "Introduce intelligent front desk for serving efficiently non eligible customers" and "Introduce new means to serve efficiently eligible customers". There is two alternative ways to accomplish the last goal: "Introduce intelligent front desk for serving efficiently eligible customers" and "Introduce adaptations of existing practices for serving efficiently eligible customers".

In summary, the goal deployment strategy allows us to take the full advantage of (i) the goal modeling activities that have been carried out along the map sections MS1 and MS2, (ii) the result of the brainstorming sessions performed to define the contextual forces and the future goals of the company along the map section MS3. The guideline suggested for the map section MS4 recommends an intention-driven modeling process which results in a hierarchy of change goals including the alternative roads to be followed by the enterprise in order to reach the envisioned future state.

IV.2.5. Evaluating the alternative change scenaria and selecting the most appropriate ones: 'Alternative scenaria evaluated and the most appropriate ones selected' state

Selection of an optimal change option is carried out through comparative evaluation of alternative scenarios within the change process model. The map section MS5: <Elicit Enterprise Goal Structure, Elicit Enterprise Goal Structure, Evaluation Strategy> supported the selection of the most appropriate change solution.

In order to obtain a more manageable number of scenaria prior to evaluations, the guideline associated to this map section suggests first, to prune the change process model. Pruning consists in removing alternatives in the hierarchy of change goals using strategic criteria. In order to limit the complexity of the evaluation process, each branch of the pruned change process model is considered separately. After a natural language description of all possible scenaria within a branch, several stakeholders evaluate each scenario. Then, individual results are aggregated and the average scoring of the scenario for each criterion is presented in a summary table. A preferred set of scenaria is selected by branch by comparing one scenario against another on their respective scores. Finally, the appropriateness of the preferred scenaria defined separately as sets of branch scenaria are globally evaluated. This can result in backtracking on choices made locally. The preferred set of scenaria is then documented and recommendations for the selection of the most suitable ones are provided.

The following algorithm describes the scenaria evaluation process encapsulated into this guideline:

1) Inspect and prune the change process model

For each branch

2) Compile the list of scenaria 
3) Evaluate scenaria using criteria in a qualitative manner

4) Assess the level of agreement of the qualitative evaluation of each scenario

5) Evaluate scenario with no consensus using metrics in a quantitative manner

6) Assess the level of agreement of the quantitative evaluation of each scenario

7) Choose preferred set of scenaria based on a comparative evaluation

8) Perform global evaluation

9) Derive the preferred set of scenaria

Let us first introduce the notion of scenario with an example. A scenario is defined as a sub-hierarchy of change goals that are related through AND relationships only. The example presented in Figure 16 is an excerpt of the Distribution Unit change process model. This hierarchy describes several ways of fulfilling the goals "Serve efficiently non eligible customers", "Introduce new means to serve efficiently eligible customers", and "Introduce a customer oriented culture". Each distinct combination of these ways gives rise to different scenaria. The generation of these alternative scenaria comes from the OR and AND/OR relationships.

A scenario is one solution to achieve a change goal. Figure 17 shows two scenaria among the $124\left(\left(2^{5}\right.\right.$ -1) $\times 2 \times 2$ ) which can be generated from the change process model of Figure 16. In can be noticed that a scenario does not include OR and AND/OR relationships.

As an illustration of the scenaria evaluation process, let us consider the excerpt of the Distribution Unit change process model of Figure 16.

Step 1 aims at pruning this hierarchy of change goals in order to limit the number of scenaria to be examined evaluated and compared in the following steps. Thus, the set of alternatives related to AND/OR and OR relationships is evaluated against the strategic criteria. The removal of alternatives based on this evaluation produces the pruned change process model.

Step 2 consists in producing all possible scenaria within a branch [35]. A formal procedure is defined to automatically produce these alternative branch scenaria. Then, each identified scenario is named and described by the collection of the leaf goals and in natural language. For instance, Scenario $\mathcal{S}$ contains the leaf goals "Maintain the safe and continuous provision of electricity" and "Introduce intelligent front desk for serving efficiently non-eligible customers" and its description in natural language is the following: "Introduce information front desk as a re-engineering project. The change will involve complete redesign of service processes and supporting IT systems. The implementation horizon is 5 years and focused on non-eligible customers." 


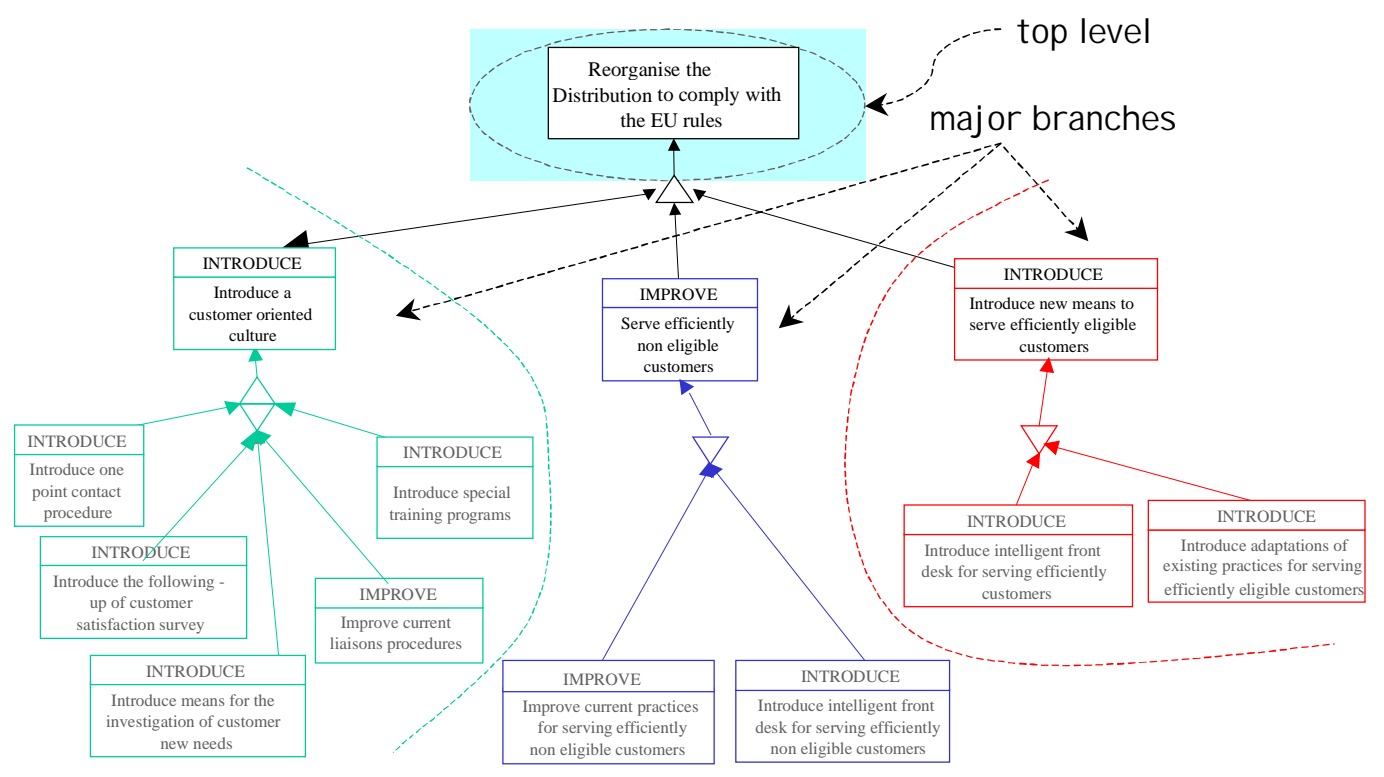

Figure 16: An excerpt of the Distribution Unit change process model

The conformance of a scenario to some criterion can be supported or hindered by arguments for and against the scenario. Business experts express such arguments. Step 3 consists first, in collecting individual opinions by scoring the scenario against each established criterion (feasibility to deliver in the given time frame, added value, cost). The individual results are then aggregated and the average scoring for each criterion is presented in a summary table

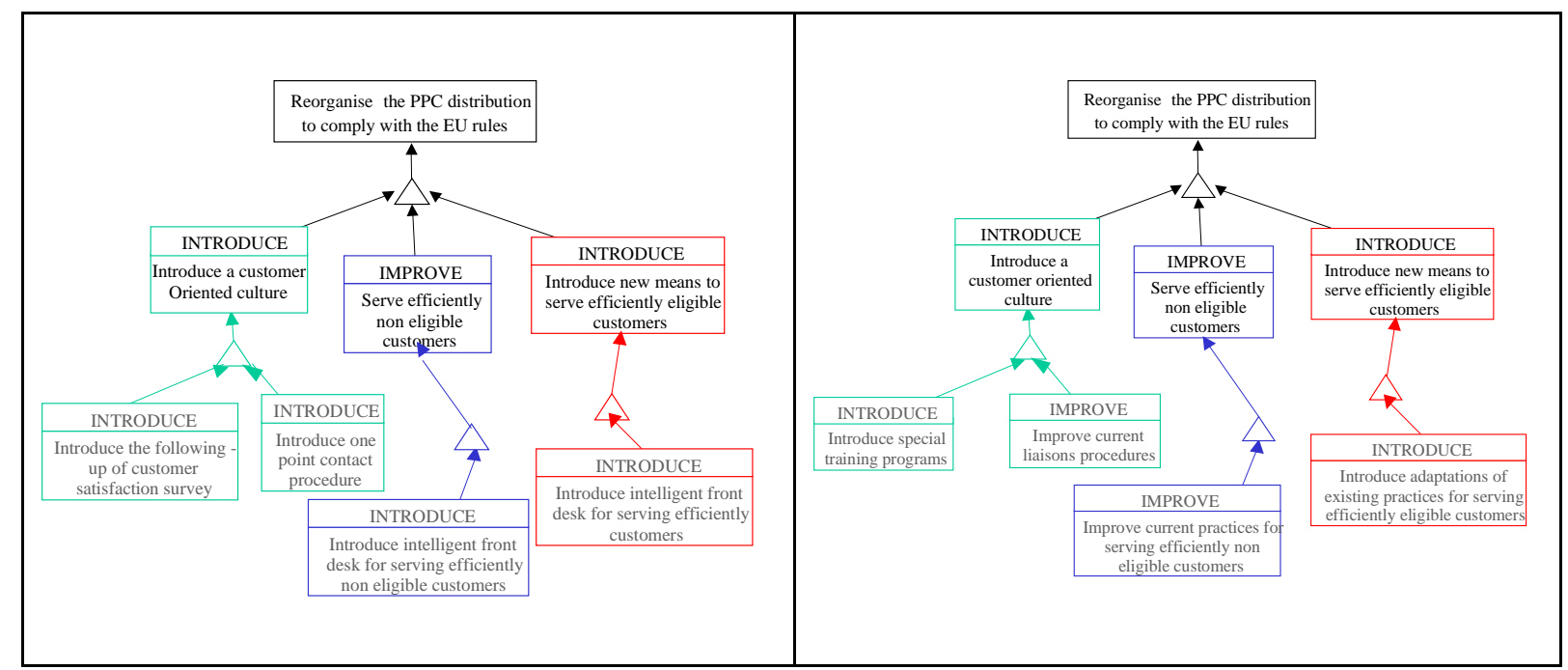

Figure 17: Two examples of scenario

Step 4 aims to guarantee that the level of agreement between individual evaluations is high. This level is to be decided by the participants. As an example, let us consider the case where the stakeholders evaluate the individual scenario "Introduce information front desk for serving non-eligible customers". If some of the voters evaluated the scenario as Low and some of them as Very High in terms of satisfying the criteria 'Cost', then such contradictions should be pointed out at this step. If the contradiction remains after discussion then step 5 is performed.

Step 5 aims, for every scenario with low consensus, at a quantitative evaluation based on the use of 
metrics. We adopted the GQM (Goal-Question-Metric) approach which recommends goal-oriented measurement, i.e. all data collection in a measurement program should be based on a rationale that is explicitly documented [2]. This approach consists in deriving a set of metrics by setting (a) goals, (b) questions refining goals and (c) metrics to measure goal achievement (see Figure 18). Alternative scenaria are then, evaluated by giving a value to each metric. Individual opinions are collected and aggregated in a summary table (see Figure 19).

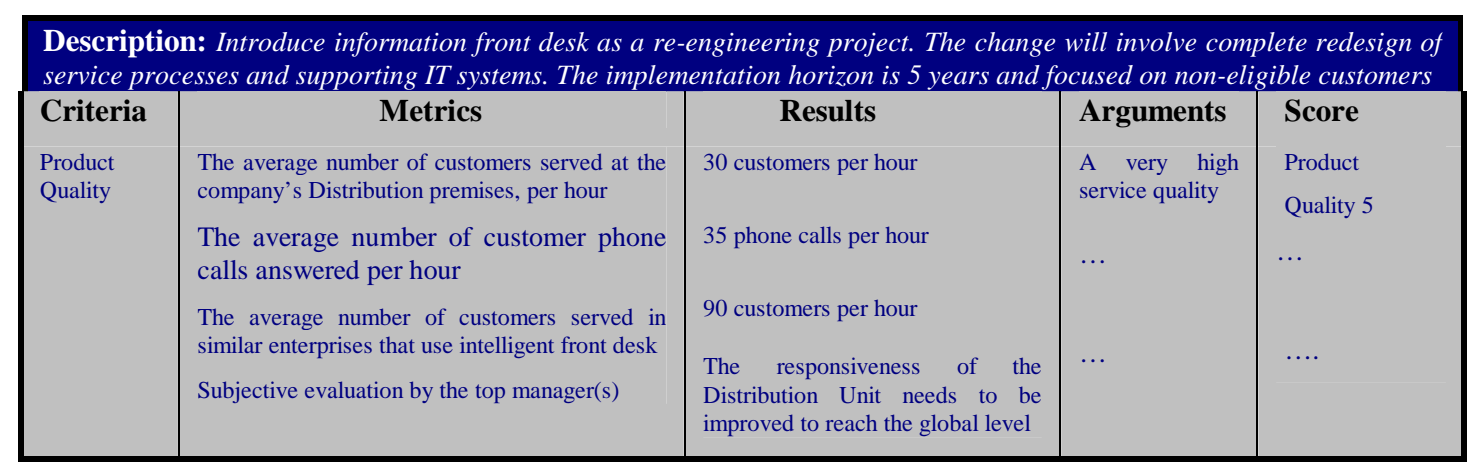

Figure 18: Quantitative Evaluation Table

Step 7 organizes a comparative evaluation of scenaria by comparing one scenaria against another on their respective scores acquired in previous steps. A comparison table summarizing the scoring of all scenaria is automatically built using previous evaluation tables. An example of comparative evaluation table is given in Figure 19.

\begin{tabular}{|l|l|l|l|l|l|l|l|}
\hline $\begin{array}{l}\text { CRITERIA } \\
\text { SCENARIA }\end{array}$ & $\begin{array}{l}\text { Feasibility to deliver in } \\
\text { the given time frame }\end{array}$ & $\begin{array}{l}\text { Added } \\
\text { Value }\end{array}$ & Cost & $\begin{array}{l}\text { Balance of } \\
\text { Concerns }\end{array}$ & $\begin{array}{l}\text { Product } \\
\text { Quality }\end{array}$ & $\begin{array}{l}\text { Produc- } \\
\text { tivity }\end{array}$ \\
\hline BRANCH_2 & 14 & 8 & 10 & 11 & 15 \\
\hline $\begin{array}{l}\text { Improve current practices for serving } \\
\text { efficiently non-eligible customers }\end{array}$ & 12 & 16 & 10 & 12 & 14 & 17 \\
\hline $\begin{array}{l}\text { Introduce intelligent front desk for serving } \\
\text { efficiently non-eligible customers }\end{array}$ & 14 & 14 & \\
\hline
\end{tabular}

Figure 19: An example of a Comparative Evaluation Table

As seen in Figure 19, in Branch 2 (Figure 16) there exist two options. The first option suggests the improvement of existing practices while the second opts for the introduction of intelligent front-desk. The final markings per criterion for both scenaria are also shown. With this overall table the stakeholders can select one preferred scenario per branch. In this example such a preferred scenario could be 'Introducing intelligent front desk for serving efficiently non-eligible customers'.

Step 8 studies the interdependencies among choices made previously per branch. The global preferred scenaria resulting of the union of preferred branch scenaria can be globally unsustainable for the organization, for example in terms of costs or human resources. It could be necessary to make more modifications assuming that scenaria from different branches have strong negative impacts on each other.

Finally, step 9 aims to finalize and document the preferred set of scenaria and to provide recommendations for the selection of the most suitable ones. 
As a result of the alternative scenaria evaluation, the enterprise can capture the rationale behind the decision making process and record the associated deliberation process ${ }^{[}$The capitalized knowledge can be reused when other decisions are made.

In summary, selection of an optimal change option was carried out through comparative evaluation of alternative scenarios within the change process model. Ranking the evaluation goals with respect to their relative importance proved to be of assistance. Both scenario evaluation as well as interpretation of evaluation data was dependent on subjective judgement of involved participants. Disagreement between stakeholder judgements was alleviated by the use of voting procedures.

\section{Conclusion}

This paper reports on the use of an intentional framework for modeling organizational change. A major advantage of the proposed approach is the systematic way of dealing with change in terms of enterprise knowledge modeling used with a process guidance framework.

The EKD-CMM framework provides users of the EKD-CMM with the possible routes of using the method depending on their intentions, the methodological situation they are in, and the tools available to them. The EKD-CMM engineer may follow a variety of routes making use of a variety of techniques. Nevertheless, we believe that mastering the change in an organization requires four key states to be reached while modeling with EKD-CMM. These are the 'As-Is' state defining the current business processes and objectives, the 'Alternative scenaria for change determined' defining the alternative scenaria for describing the possible alternative routes to be followed by the enterprise in order to reach its envisioned future state, the 'Alternative scenaria evaluated and one selected' as a result of the evaluation of the alternative scenaria, and the 'To-Be' state defining the future business processes and goals.

The benefits for the studied company for having used the method presented in this paper are the following: (a) The systematic and guided search for alternative manners to achieve a change goal helped the stakeholders to envisage innovative solutions; (b) Because the goal deployment strategy uses as input the 'As-Is' state, the stakeholders were able to point the impacts of the change they proposed on the existing processes; (c) Using the change process model, the stakeholders were able to carry out an informed evaluation of the alternative scenaria for change to select the most appropriate one.

The experience gained during this study has substantiated the view that the route to be followed in a particular change project is very much dependent on the enactment context of the project. The selection of the bottom-up route was influenced by the uncertainty regarding both the current Distribution Business Unit situation and its possible re-organization alternatives. Application of the specific strategies forming this route was also affected by a number of situational factors including:

${ }^{9}$ According to the specificities of decision oriented Process Models highlighted in section 2.1. 
1. organizational culture, e.g., organizational actors that were not used to working in groups in a participative way, felt awkward in such a situation and found it difficult to contribute as intended;

2. ability to commit resources, e.g., the quality of the enterprise models largely depended in the participation of the 'right' people both in terms of business experts and method experts;

3. social skills and consensus attitudes of participating actors, e.g., conflicts between individuals and groups within the project increased the complexity of the situation;

4. use of software tools to facilitate the process execution, e.g., the use of group support technologies in participative sessions increased both productivity and the quality of results obtained; and

5. familiarity with applied strategies and supporting technologies, understanding, among project participants, of the capabilities and limitations of the strategies and tools applied was vital in order to make the best use of them and to produce useful results.

The implication of these empirical observations is that the change management process cannot be fully prescribed. Even when one follows a certain strategy the situational factors dominating the project may cause a number the adaptations to this strategy. This fact strengthens the position advocated by the EKD-CMM road map that in order to support the execution of change processes flexible guidelines are more relevant than rigid rules. For example, the second application that takes place in a Scandinavian country used a different route of the road map completely excluding the analyst driven strategy and using largely the participative modeling one. Thus, the Enterprise Knowledge Development - Change Management Method applied in the ELEKTRA project provided a systematic, nevertheless flexible, way to organize and to guide the change process, and resulted in the expression of reusable knowledge tailored to the change management.

\section{Acknowledgements}

The authors wish to acknowledge the support and collaboration of Strategy and Distribution personnel of Public Power Corporation (Greece) and to express their gratitude to all their partners within the ELEKTRA project. 


\section{References}

1. Barrett, J.L. Process visualization. Getting the vision right is key. Information Systems Management (Spring 1994), 14-23.

2. Basili, V.R., Caldiera, G., and Rombach, H.D. Goal question metric paradigm. In Marciniak, J. (ed.) Encyclopaedia of Software Engineering, Vol 1, John Wiley \& Sons, 1994, 528-532.

3. Bubenko, J. Enterprise Modeling. Ingénierie des Systèmes d'Information, Vol 2, № 6 (1994).

4. Bubenko, J., and Stirna, J. EKD User Guide. ELEKTRA project, Research report, February 1997.

5. Checkland, P. and Scholes, J. Soft Systems Methodology in Action, John Wiley and Sons, 1990.

6. Curtis, B., Kellner, M. and Over, J. Process Modeling. Communications of ACM, 35, 9 (1992), 75-90.

7. Decker, S., Daniel, M., Erdmann, M. and Studer, R. An enterprise reference scheme for integrating Model based knowledge engineering and enterprise modeling. $10^{\text {th }}$ European Workshop on Knowledge Acquisition, Modeling and Management, EKAW'97, Lecture Notes in Artificial Intelligence, Springer-Verlag, Heidelberg, 1997.

8. DeMarco, T. Structured Analysis and System Specification, New Jersey: Prentice-Hall, 1979.

9. Dowson, M. Iteration in the Software Process. 9th International Conference on Software Engineering (1987).

10. Dowson, M. and Fernstrom, C. Towards requirements for enactment mechanisms. European Workshop on Software Process Technology, 1994.

11. Emmerich, W., Junkermann, G. and Schafer, W. MERLIN: Knowledge-based process modeling. First European Workshop on Software Process Modeling, Milan, Italy, 1991.

12. Espejo, R. and Harnden R. (eds). The Viable System Model: Interpretations and Applications of Stafford Beer's VSM, Chichester: Wiley, 1989.

13. Ellis, C.A., Information Control Nets, A Mathematical Model of Office Information Flow. ACM Conference on Simulation, Measurement and Modeling of Computer Systems (1979), 225-240.

14. Ellis, C.A., Wainer, J., Goal-based models of collaboration. Collaborative Computing, 1, 1, 1994.

15. Finkelstein, A., Kramer, J. and Goedicke, M. ViewPoint Oriented Software Development. Conference "Le Génie Logiciel et ses Applications", Toulouse (1990) 337-351.

16. Finkelstein, A., Kramer, J. and Nuseibeh, B. (eds). Software Process Modeling and Technology. John Wiley Pub., 1994.

17. Flood, R.L. and Jackson, M.C. Creative Problem Solving. Total System Intervention, John Wiley and Sons Ltd, 1991.

18. Gotel, O. and Finkelstein, A. An Analysis of the Requirements Traceability Problem. First IEEE International Conference ICRE'94, Colorado Springs, USA (1996).

19. Grosz, G., Rolland, C., Schwer, S., Souveyet, C., Plihon, V., Si-Said, S., Ben Achour, C., and Gnaho, C. Modeling and engineering the requirements engineering process: an overview of the NATURE approach. Requirements Engineering Journal, $\mathrm{N}^{\circ} 2$ (1997), 115-131.

20. Grover, V., Fiedler, K.D. and Teng, J.T.C. Exploring the success of information technology enabled business process reengineering. IEEE Transactions on Engineering Management, Vol. 41, № 3 (August 1994), 276-283.

21. Guha, S., Kettinger, W.J. and Teng, J.T.C. Business process reengineering, building a comprehensive methodology. Information System Management (Summer 1993), 13-22.

22. Hammer, M., and Champy J. Re-engineering the Corporation: A Manifesto for Business Revolution. New York: Harper Collins Publishers, inc., 1993.

23. Harel, D. STATEMATE: A working environment for the development of complex reactive systems. IEEE Transactions on Software Engineering, 16, 4, (April 1990), 403-414.

24. Humphrey, W.S. Managing the Software Process, Addison-Wesley, 1989.

25. Hung, K., Simons, T. and Rose, T. The truth is out there? : a survey of business objects. International Conference on Object oriented Information Systems, Paris, France, September 1998, 183-200.

26. Jacherri, L., Larseon, J.O. and Conradi, R. Software process modeling and evolution in EPOS. 4th International Conference on Software Engineering and Knowledge Engineering (SEKE'92), Capri, Italy (1992).

27. Jackson, M. Software Requirements and Specifications - A Lexicon of Practice, Principles and Prejudices. Addison Wesley Press, 1995. 
28. Jacobson, I., Chisreton, M., Jonsson, P. and Overgaard, G. Object Oriented Software Engineering - A Use Case Driven Approach, Addison-Wesley, 1993.

29. Jarke, M., Mylopoulos, J., Schmidt, J.W. and Vassiliou, Y. DAIDA - An environment for evolving information systems. ACM Transactions on Information Systems, 10, 1, 1992.

30. Jarzabek, S., and Ling, T.W. Model-based support for business reengineering. Information and Software Technology, $\mathrm{N}^{\circ}$ 38 (1996), 355-374.

31. Kavakli, V., and Loucopoulos, P. Goal-driven business process analysis: application in electricity deregulation. 10th International Conference on Advanced Information Systems Engineering (CAiSE'98), B. Pernici (ed.), Springer-Verlag, Pisa, Italy $(199,305-324$.

32. Lonchamp, J. A structured conceptual and terminological framework for software process engineering. International Conference on Software Process (1993).

33. Loucopoulos, P., Kavakli, V., Prekas, N., Dimitromanolaki, I. Yilmazturk, N., Rolland, C., Grosz, G., Nurcan, S., Beis, D., and Vgontzas, G. System design specification for PPC. ELEKTRA project, Demetra Deliverable (March 1998).

34. Loucopoulos, P., Kavakli, V., Prekas, N., Dimitromanolaki, I. Yilmazturk, N., Rolland, C., Grosz, G., Nurcan, S., Beis, D., and Vgontzas, G. The ELEKTRA project: Enterprise Knowledge Modeling for change in the distribution unit of Public Power Corporation. 2nd IMACS International Conference on Circuits, Systems and Computers (IMACS-CSC'98), Athens, Greece (1998), 352-357.

35. Loucopoulos, P., Kavakli, V., Prekas, I. Yilmazturk, N., Dimitromanolaki, N., Rolland, C., Grosz, G., Nurcan, Sfakianos, C. and Kenett, R. Evaluation of design alternatives. ELEKTRA project, Ermes Deliverable (September 1998).

36. Loucopoulos, P., Kavakli, V., Prekas, N., Rolland, C., Grosz, G. and Nurcan, S. Using the EKD approach: the modeling component. ELEKTRA project, Athena Deliverable (March 1997).

37. Loucopoulos, P., and Kavakli, V. Enterprise modeling and teleological approach to requirements engineering. International Journal of Intelligent and Cooperative Information Systems, Vol. 4, N 1 (1995), 44-79.

38. Medina-Mora, R., Winograd, T., Flores, R., Flores, F., The Action Workflow approach to workflow management technology. CSCW'92, ACM, Toronto, Canada, 1992.

39. McCarthy, D.R., Sarin, S.K., Workflow and transactions in InConcert. Bulletin of Technical Committee on Data Engineering., 16, 2, IEEE, Special Issue on Workflow and Extended Transactions Systems, 1993.

40. Nadin, M. and Novak, M. MIND: A design machine, conceptual framework. Intelligent CAD Systems I, Springer Verlag, 1987.

41. Nilsson, N. Problem Solving Method in Artificial Intelligence. McGraw Hill, 1971.

42. Nurcan, S., Grosz, G. and Souveyet, C. Describing business processes with a guided use case approach. 10th International Conference on Advanced Information Systems Engineering (CAiSE'98), B. Pernici (ed.), Springer-Verlag, Pisa, Italy (1998), 339-361.

43. Potts, C. A generic model for representing design methods. 11th International Conference on Software Engineering (1989).

44. Ramesh, B. A model of requirements tracebility for systems development. Technical report. Naval Postgraduate School, Monterey, CA (September 1993).

45. Rolland, C., Nurcan, S. and Grosz, G. Enterprise knowledge development: the process view. Information and Management, 36, 3, September 1999.

46. Rolland, C., Nurcan, S. and Grosz, G. A decision making pattern for guiding the enterprise knowledge development process. Information and Software Technology, 42, 5, 2000.

47. Rolland, C., Nurcan, S. and Grosz, G. A unified framework for modeling co-operative design processes and co-operative business processes. 31st Annual Hawaii International Conference on System Sciences, Big Island, Hawaii, USA, January 69, 1998.

48. Rolland, C., Grosz, G., Nurcan, S., Yue, W. and Gnaho, C. An electronic handbook for accessing domain specific generic patterns. IFIP WG 8.1 Working Conference: Information Systems in the WWW environment (July 15-17, 1998), Beijing, Chine, 89-111.

49. Rolland, C., Loucopoulos, P., Grosz and G., Nurcan, S. A framework for generic patterns dedicated to the management of change in the electricity supply industry. $9^{\text {th }}$ International DEXA Conference and Workshop on Database and Expert Systems Applications (August 24-28, 1998), 907-911.

50. Rolland, C., Nurcan, S. and Grosz, G. The goal deployment approach for modeling the change process. ELEKTRA project, Demetra Deliverable (March 1998). 
51. Rolland, C., Grosz, G., Loucopoulos, P., and Nurcan, S. A framework for encapsulating best business practices for electricity supply industry into generic patterns. 2nd IMACS International Conference on Circuits, Systems and Computers (IMACS-CSC'98), Athens, Greece (1998), 330-336.

52. Rolland, C., Nurcan, S. and Grosz, G. Guiding the participative design process. Association for Information Systems, Americas Conference on Information Systems, Indianapolis, Indiana, USA (15-17 Aug. 1997), 922-924.

53. Rolland, C., Nurcan, S. and Grosz, G. A way of working for change processes. International Research Symposium: Effective Organisations, Dorset, UK (September 4-5, 1997), 201-204.

54. Rolland, C., Grosz, G. and Nurcan, S. Guiding the EKD process. ELEKTRA project, Research Report (December 1996).

55. Rolland, C. Understanding and guiding requirements engineering processes. Invited talk. IFIP World Congress, Camberra, Australia (1996).

56. Rolland, C. and Grosz, G. A general framework for describing the requirements engineering process. IEEE Conference on Systems Man and Cybernetics, CSMC94, San Antonio, Texas (1994).

57. Rolland, C., Souveyet, C. and Moreno, M. An approach for defining ways-of-working. Information System Journal, 20, 4 (1995), 337-359.

58. Rose, T., Jarke, M., Gocek, M., Maltzahn, C. and Nissen, H.W. A decision-based configuration process environment. IEEE Software Engineering Journal, 6, 3 (1991).

59. Ross, D.T. Douglas Ross talks about structured analysis. IEEE Computer (July 1985), 80-88.

60. Marca, D.A. and McGowan, C.L. IDEF0/SADT: Business Process and Enterprise Modeling. San Diego: Eclectic Solutions, Inc., 1993.

61. Rumbaugh, J., Blaha, M., Premerlani, W., Eddy, F. and Lorensen, W. Object Oriented Modeling and Design. PrenticeHall, 1991.

62. Seligmann, P.S., Wijers, G.M. and Sol, H.G. Analysing the structure of I. S. methodologies, an alternative approach. First Conference on Information Systems, Amersfoort, The Netherlands (1989).

63. Stoddard, D.B. and Jarvenpaa, S.L. Business process redesign: tactics for managing radical change. Journal of Management Information Systems, 12, 1 (1995).

64. Swenson, K.D., Visual support for reengineering work process. Conference on Organizational Computing Systems, ACM, Milpitas, California (1993).

65. Tomiyama, T., Kiriyama, T., Takeda, H., Xue D. and Yoshikaya, H. Metamodel: A key to intelligent CAD systems. Research in Engineering Design,1 (1989) 19-34.

66. Ventana-Corporation. Ventana GroupSystems for Windows. Tuscon, Arizona, USA.

67. Wynekoop, J.D. and Russo, N.L. System Development Methodologies: unanswered questions and the research-practice gap. 14th ICIS Conference (eds. J.I. DeGross, R.P. Bostrom, D. Robey), Orlando, USA (1993), 181-190. 